\title{
Nonlinear Filtering in Oil/Gas Reservoir Simulation: Filter Design
}

\author{
E. M. Arnold \\ D. A. Voss \\ D. W. Mayer
}

October 1980

Prepared for

the U.S. Geological Survey under a Related Services Agreement with the U.S. Department of Energy

Contract DE-AC06-76RLO 1830

Pacific Northwest Laboratory Operated for the U.S. Department of Energy by Battelle Memorial Institute 
NOTICE

This report was prepared as an account of work sponsored by the United States Government. Neither the United States nor the Department of Energy, nor any of their employees. nor any of their contractors, subcontractors, or their employees. makes anv warranty, express or implied. or assumes any legal liability or responsibility for the accuracy. completeness or usefulness of any information. apparatus, product or process disclosed, or represents that its use would not infringe privately owned rights.

The views, opinions and conclusions contained in this report are those of the contractor and do not necessarily represent those of the United States Government or the United States Department of Energy.

\author{
PACIFIC NORTHWEST LABORATORY \\ operated by \\ BATTELLE \\ for the \\ UNITED STATES DEPARTMENT OF ENERGY \\ Under Contract DE-AC06-76RLO 1830
}
Printed in the United States of America Available from
National Technical Information Service United States Department of Commerce 5285 Port Royal Road
Springtield. Virginia 22151

Price: Printed Copys $\therefore$ Microfiche 53.00

-Pages Selling Price

$\begin{array}{ll}001-025 & \$ 4.00 \\ 026-050 & \$ 4.50 \\ 051-075 & \$ 5.25 \\ 076-100 & \$ 6.00 \\ 101-125 & \$ 6.50 \\ 126-150 & \$ 7.25 \\ 151-175 & 58.00 \\ 176-200 & \$ 9.00 \\ 201-225 & \$ 9.25 \\ 226-250 & \$ 9.50 \\ 251-275 & \$ 10.75 \\ 276-300 & \$ 11.00\end{array}$




\section{1}

NONLINEAR FILTERING IN OIL/GAS RESERVOIR

SIMULATION: FILTER DESIGN
E. M. Arnold
D. A. Voss
D. W. Mayer

October 1980

Prepared for the U.S. Geological Survey under a Related Services Agreement with the U.S. Department of Energy Contract DE-AC06-76RLO 1830

Pacific Northwest Laboratory Richland, Washington 99352 


\section{SUMMARY}

In order to provide an additional mode of utility to the USGS reservoir model VARGOW, a nonlinear filter was designed and incorporated into the system. As a result, optimal (in the least squares sense) estimates of reservoir pressure, liquid mass, and gas cap plus free gas mass are obtained from an input of reservoir initial condition estimates and pressure history. These optimal estimates are provided continuously for each time after the initial time, and the input pressure history is allowed to be corrupted by measurement error. Preliminary testing of the VARGOW filter was begun and the results show promise. Synthetic data which could be readily manipulated during testing was used in tracking tests. The results were postive when the initial estimates of the reservior initial conditions were reasonably close. Further testing is necessary to investigate the filter performance with real reservoir data. 


\section{CONTENTS}

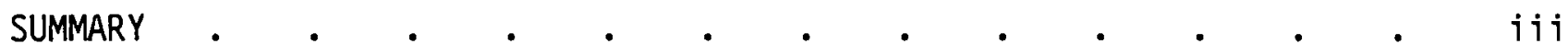

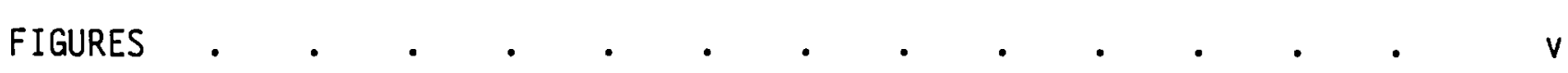

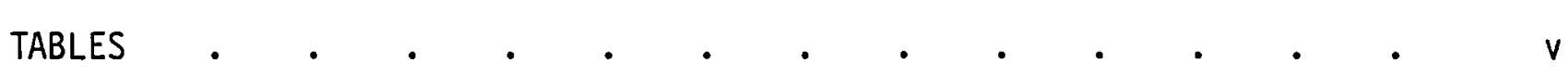

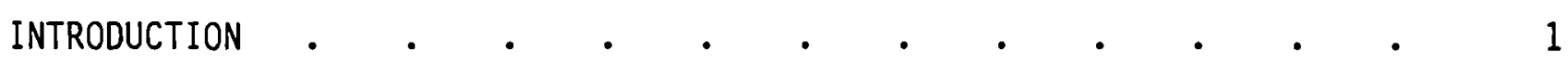

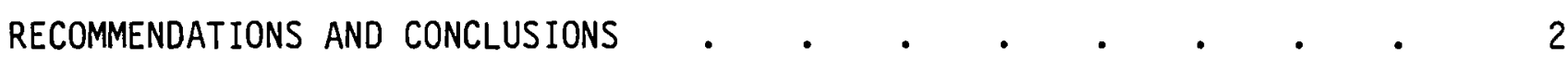

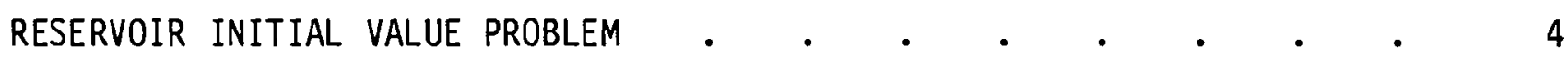

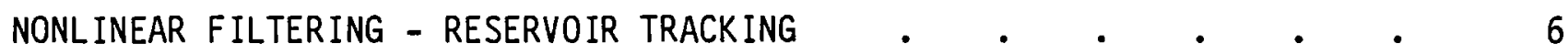

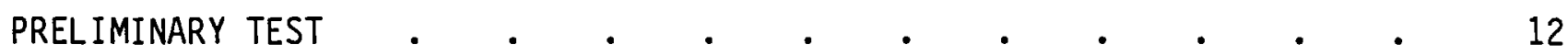

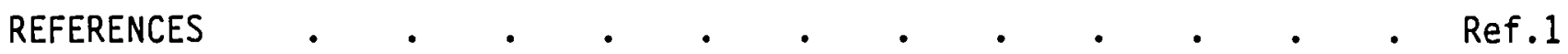

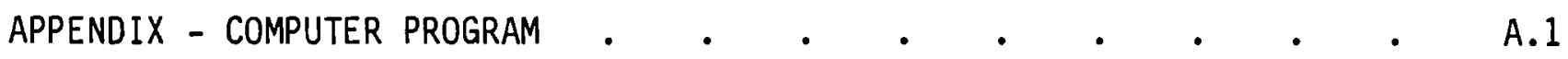




\section{FIGURES}

1 Actual Versus Filtered Pressure . . . . . . . . 14

2 Actual Versus Filtered Total Liquid . . . . . . 15

3 Actual Versus Filtered Total Gas . . . . . . . 16

$\underline{\text { TABLES }}$

1 Input Parameter Values . • . • . . . . . 12 
INTRODUCTION

The physical structure of the variable gas-oil-water (VARGOW) reservoir per se model can be described as a zero-dimensional tank-piston model. "Zerodimensional tank-piston" implies that spatial variations are not considered and the reservoir is treated as a large tank with any inflowing aquifer water forming a piston that pressurizes the reservoir. The "piston" is assumed to be porous to allow entrapment of the reservoir material ( $0 i 1$ and gas) by the invading water. The term "reservoir per se" indicates that the model considers only the reservoir itself and does not consider individual wells drilled into the reservoir. The reservoir model was developed by the U.S. Geological Survey with the objective of providing recovery estimates that are suitable for assessment of various reservoir production policies with regard to production regulation.

The purpose of this report is to discuss the modification of VARGOW to employ a nonlinear filter algorithm. The section following the Recommendations and Conclusions discusses the reservoir initial value problem. The next section discusses reservoir tracking using a nonlinear filter algorithm and developes the algorithm as used in the VARGOW model. The final section presents the results obtained from a preliminary test of the filter algorithm. 


\section{RECOMMENDATIONS AND CONCLUSIONS}

1. The results of preliminary testing indicate that the filtered version of VARGOW can be useful as a reservoir tracking device which reads a noisy pressure record and gives updated optimal estimates of pressure, liquid content, and gas content of the reservoir. This increases the scope and utility of the VARGOW model as a tool for the planning and execution of reservoir operation strategies.

2. The speed of convergence of the filter depends upon the quality of the beginning estimate of the reservoir initial state. This estimate is an input to the filter and must be at least a "ball park" guess if the filter is to converge at all. A testing procedure should be designed which would quantify the effect on filter convergence of initial condition accuracy.

3. It can be advantageous to run the filtered version of VARGOW for some initial segment of the reservoir history to establish an optimal beginning point for a subsequent use of VARGOW without the filter. This would allow an improved prediction capability which should be tested in further research.

4. It is possible to use the filter to estimate parameters characterizing reservoir media properties, entrapment mechanisms and gas migration. If $\alpha$ denotes such a parameter, the equation $d \alpha / d t=0$ is added to the filter system. In this way an optimal estimate of $\alpha$ is obtained subject to the minimization of the observed and calculated pressure. This procedure should be tested to find out how many parameters can be efficiently estimated. There is a trade off between the number of parameters to be estimated and the size of the resulting filter system.

5. The possibility of using the gas/oil ratio as an auxilary tracking variable should be investigated.

6. The addition of the estimator equations for the optimal estimate $e$ and the weighting matrix $Q$ adds to the size and complexity of the system. This results in numerical problems with the ordinary differential equation solver in VARGOW. At present it is necessary to use very small time steps 
in the filter because of system stiffness (i.e. the system includes both rapidly and slowly varying terms). This is expensive for long simulations. Modification of the Runge-Kutta integration scheme in VARGOW may be necessary. 


\section{RESERVIOR INITIAL VALUE PROBLEM}

The simulation of $0 i 1 /$ gas reservoirs with water entrapment using the VARGOW model proceeds via the solution of an initial value problem. The state of the reservoir at any time is given by the set of quantities $\left[P(t), N_{L}(t)\right.$, $\left.N_{F G C}(t)\right]$ where $P, N_{L}$, and $N_{F G C}$ are the reservoir pressure, mass of liquid, and mass of free plus gas-cap gas, respectively. Certainly there are many other intermediate quantities described with in the VARGOW model, but these three are the primitive variables in the sense that all the others can be derived from them. The evolution of the reservoir state from an initial state is determined by the solution of a system of three coupled nonlinear ordinary differential equations which can be written as:

$$
\frac{d x^{i}}{d t}=f^{i}\left(x_{1}, x_{2}, x_{3}\right), i=1,2,3
$$

where $x_{1}=P, x_{2}=N_{L}, x_{3}=N_{F G C}$ and the functions of $f^{i}$ are the righthand sides of equation (106), (107), and (108) in SAD section report number 77-10 (USGS 1976) which gives the mathematical description and terminology of the VARGOW model. This simplified notation allows a cleaner discussion of the filtering problem.

The model parameters characterizing the media properties of the reservoir, water entrapment mechanisms, and gas/oil phase properties are estimated by a combination of statistical and physical means. These parameters appear in the functions $f^{i}$ in Equation (1) and serve to specialize the model equations to a particular reservoir. After the parameters are estimated, the VARGOW mode 1 calculates the reservoir state through a numerical solution of Equation (1) from an input of reservoir initial conditions $P^{0}, N_{L}^{0}$ and $N_{F G C}^{0}$.

Even when the parameters are accurately estimated, the accuracy of the calculations are limited by the precision with which the inital conditions are determined. The initial conditions are usually obtained from field measurements and laboratory tests. There is enough physical content to these values 
that they should not be "floated" in a statistical estimation procedure. On the other hand they are still obscured by measurement errors, and sampling methods which don't respresent the bulk properties of the reservoir.

Furthermore, since the simulation proceeds from a fixed initial condition, errors caused by inaccurately determined initial conditions are felt throughout the entire simulation. In effect, if a bad guess at initial conditions is made at the start, one is stuck with it.

As an alternative to the use of VARGOW in a pure initial value problem, as just described, the model can be incorporated into a nonlinear filtering procedure. The filtering algorithm accepts observations (perhaps noisy) on the reservoir state as well as model calculations as ingredients in an optimization scheme which continuously minimizes the least squares difference between the calculated and measured reservoir state. Thus, in the filtering mode, the VARGOW model calculations are influenced, not just by a fixed initial condition, but by a continuous record of noisy measurements on at least one of the state variables $P, N_{L}$ or $N_{F G C}$. Roughly speaking, the reservoir state is being continuously updated so that the mean square error between calculated and observed records is minimized. 


\section{NONLINEAR FILTERING PROBLEM - RESERVOIR TRACKING}

Most of the literature on filtering is specialized to linear systems with complete statistical knowledge of the measurement or observation errors. For example, the celebrated Kalman Filter (Kalman and Bucy 1961) assumes the system model can be expressed as stochastic differential equations with the disturbances being stochastic processes (usually Gaussian) with orthogonal increments.

The approach taken in this study is based upon the invariant imbedding ideas of Bellman (1964). This method is applicable to nonlinear systems, such as VARGOW, and makes no essential use of the statistics (often unknown) of the measurement errors. It should be noted, however, that when statistical information about the disturbances is known, the information may be used to improve the optimization algorithm. For example, these statistics may indicate that an object function other than least squares is appropriate for the minimization.

To simplify the ideas involved in the filtering algorithm, a simple scalar system will be considered first. After this, the filter for VARGOW can be formulated with only minor modifications. This exposition closely follows (Kagiwada 1974, Ch 9) and (Lee 1968, Ch 8) which are basic references for this report.

Consider a scalar system whose state evolves through time $t$ as a solution of the nonlinear ordinary differential equation:

$$
\frac{d x}{d t}=f(x, t)
$$

The system state is observed from the initial time, taken as $t=0$, up until the present time $t=T$. Due to measurement errors, the true state $x(t)$ is corrupted by a noise component. Thus, the observed state $z(t)$ can be written as $z(t)=$ $x(t)+n(t)$, where $n(t)$ is the noise or disturbance. It is desired to estimate 
the state $x(t)$ at time $T$, based upon observations over the time interval $[0, T]$ in such a way that the mean square difference:

$$
\int_{0}^{T}[x(t)-z(t)]^{2} d t
$$

is minimized. In other words, an estimate $c$ of $x(T)$ is required such that if $x(t)$ is the unique solution of Équation (2) satisfying $x(T)=c$, then the mean square difference between $x(t)$ and the observations $z(t)$ is minimized over $[0, T]$.

The above integral object function for minimization can be written as a function of $T$ and the estimate $c$ as follows:

$$
\int_{0}^{T}[x(t)-z(t)]^{2} d t=r(c, t)
$$

At this stage, the invariant imbedding idea enters. The original process for fixed $T$ and $C$ is imbedded in a continuous family of processes for $T \geq 0$ and $-\infty<c<+\infty$. The object function is then treated as a differentiable function of $T$ and $c$. Then, using Taylors theorem along with Equations (1) and (2), the following result is obtained:

$$
r_{T}=[z(t)-c]^{2}-f(c, T) f_{c}
$$

where subscripts indicate partial differentiation. This equation is the bas is for deriving the estimator equations that constitute the filter algorithm. Also required is a side condition which together with (3) determines $r$. The 
initial data $r(c, 0)$ suffices for this purpose. It is assumed that $r(c, 0)=$ $k\left(c-c_{0}\right)^{2}$ where $c_{0}$ is an estimate of the initial condition $x(0)$ and $k$ is a scale factor expressing confidence in the estimate $c_{0}$ (small $\mathrm{k}$ means little confidence). In the preceeding discussion the current time $T$ was fixed for the estimation of $x(T)$.

An estimate for every time $T \geq 0$ is needed. These estimates are denoted by $e(T)$ for $T \geq 0$. Since $e(T)$ are the values of $c$ which minimize $r(c, t)$, it follows that $r_{c}(e, T)=0$. Writing out the total derivative $d r_{c}=0$ and solving for de/dt, it is found that:

$$
\frac{d e}{d T}=\frac{-r_{c T}(e, T)}{r_{c c}(e, T)}
$$

This equation is an estimator which will be appended to the system equation (1) with the initial condition $e(0)=c_{0}$, and solved for the optimal estimate $e(T)$ of $x(T)$. First, the functions $r_{c t}$ and $r_{c c}$ appearing in Equation (5) must be determined. Differentiating Equation (3) with respect to $c$ and solving for the expression $-r_{C T} / r_{C c}$, it is seen that the estimator Equation (5) becomes:

$$
\frac{d e}{d T}=f(e, T)+q(T)(z-e)
$$

where the factor $q(T)=2 /\left\{r_{c c}[e(T), T]\right\}$. Thus, the estimator equation has the same right-hand side as the original system equation (1) (with the variable $T$ replacing $t$ ) except for the addition of the term $z$ - e weighted by $q(T)$. This correction term expresses the weighted difference between observed and calculated values.

Finally, to complete the filter system a differential equation for $q$ is needed. This equation is obtained by differentiation of the expression defining $q$ and further differentiation of Equation (3). The details, which can be 
found in Kagiwada (1974, p. 184-186), would add no further understanding to the filter structure. The result is (neglecting $f_{c c c}$ ):

$$
\frac{d q}{d T}=2 f_{c}(e, T)\left(q-q^{2}\right)
$$

The system Equation (1) (with T replacing t) along with Equations (6) and (7) make up the filter for the scalar example.

In the VARGOW model the governing equation is a vector system for $\left(P, N_{L}\right.$, $N_{F G C}$ ), but the above analysis can be followed without introducing any new ideas. Only notational changes with vectors and matrices appearing in the place of scalars are required. These somewhat tedious modifications can be found in (Lee 1968, pp. 257-260). The final equation will be presented below.

Since data are available only for pressure, only pressure will be observed. The estimates of the reservoir state $\left[P(T), N_{L}(T), N_{F G C}(T)\right]$ for each $T \geq 0$ will minimize the object function:

$$
J=\int_{0}^{T}\left[P(t)-P_{o b}(t)\right]^{2} d t
$$

where $P_{o b}$ is the observed pressure. Thus, the filter uses the pressure as a tracking variable to obtain estimates of all of the variables ( $P, N_{L}, N_{F G C}$ ) minimizing the above object function. Note that this minimization effects all the state variables because the system is coupled.

To write the estimator equations for the VARGOW model we make some notational changes for clarity. The symbols appearing in the definitions are given in SAD section report number 77-10 (USGS 1976).

Let

$$
x=\left(x_{1}, x_{2}, x_{3}\right)^{\top}, x_{1} \equiv P, x_{2} \equiv N_{L}, x_{3} \equiv N_{F G C}
$$


Superscript $T$ denotes transpose.

$$
\begin{aligned}
& f_{1}=b_{1} \frac{(\beta-\rho \gamma)}{W}+\frac{b_{2} \gamma}{W}-\frac{b_{3} \beta}{W} \\
& f_{2}=b_{1} \frac{(a \gamma-\beta \psi)}{W}-\frac{b_{2}^{\gamma}}{W}+\frac{b_{3} \beta}{W} \\
& f_{3}=b_{1} \frac{(\rho \psi-a)}{W}+\frac{b_{2}(1-\psi)}{W}+\frac{b_{3}(a-\zeta)}{W} \\
& F=\left(f_{1}, f_{2}, f_{3}\right)
\end{aligned}
$$

Now the VARGOW system can be written in vector form:

$$
\dot{x}=\left(\dot{x}_{1}, \dot{x}_{2}, \dot{x}_{3}\right)^{\top}=F(x, t)
$$

letting

$$
r=\left(0,0,{ }_{0}^{T}\left[x_{3}{ }^{o b}(\xi)-x_{3}(\xi)^{2} d \xi\right]\right.
$$

where $x_{3}=$ pressure and

$$
\begin{aligned}
e & =\left(e_{1}, e_{2}, e_{3},\right)^{\top} \\
Q & =\left(q_{i j}\right) \\
i, j & =1,2,3
\end{aligned}
$$


the estimator equations that are appended to Equation (8) to form the VARGOW filter are:

$$
\begin{gathered}
\frac{d e}{d T}=F(e, T)+Q(T)[0,0,1]^{T}\left\{x_{3}{ }^{o b}(T)-e_{3}(T)\right\} \\
\frac{d Q}{d T}=J_{f}(e, T) Q(T)+Q(T) J_{f}(e, T)^{T}-Q(T)[0,0,1]^{\top}[0,0,1] Q(T)
\end{gathered}
$$

where $e$ is the vector of optimal estimates of $P, N_{L}$, and $N_{F G C}$ at time $T$, and $Q$ is a matrix of weighting factors analagous to $q(T)$ in Equation (6). Thus, $Q$ is the matrix:

$$
Q=2\left[\frac{\partial^{2} r^{i j}(e, T)}{\partial e^{i} \partial e^{j}}\right]^{-1}
$$

The term $J_{f}(e, T)$ is the Jacobian matrix:

$$
J_{f}(e, T)=\left[\frac{\partial f^{i}}{\partial x^{j}}\right]
$$

The system comprised of Equations (8), (9), and (10) is the VARGOW filter and its corresponding computer program is given in the appendix. 


\section{PRELIMINARY TEST}

A preliminary test of the filter algorithm as installed in the VARGOW model has been accomplished by performing a numerical experiment. The basic experiment consist of checking "actual" data with the "filtered" results that are based on a "noisy" input pressure history.

The so-called "actual" data has been generated by the VARGOW model without the filter algorithm in place. The VARGOW model has been run with the input parameters listed in Table 1 . The "actual" data is the resulting values for pressure, total gas, and total liquid that are predicted on a yearly basis.

Operation of the VARGOW model with the filter algorithm requires the input of a possibly "noisy" history of one of the state variables. For this experiment the "actual" pressure data was perturbed by a random noise component. The random noise component was taken to be a random value on the range -0.6 psi

TABLE 1. Input Parameter Values (see USGS 1976 for Notation)

\begin{tabular}{|c|c|}
\hline Parameter & Value \\
\hline a & 0.0 \\
\hline b & 8.0 \\
\hline C & 0.0 \\
\hline D & 5.0 \\
\hline $\mathrm{F}$ & 2.0 \\
\hline G & 0.4 \\
\hline$N_{L}^{0}$ & 1.0 \\
\hline P & 1000.0 \\
\hline$r_{0 I L}^{0}$ & 0.001 \\
\hline $5^{0}$ & 0.65 \\
\hline$T^{0}$ & 400.0 \\
\hline$v \rho$ & 4.0 \\
\hline$v_{R}$ & 1.15 \\
\hline$\triangle O I L$ & 0.15 \\
\hline MODEL & 5 \\
\hline
\end{tabular}


thru $0.6 \mathrm{psi}$. This results in a noise component that is up to $\pm 0.1 \%$ of the "actual" pressure. The resulting pressures have been used as the "noisy" pressure input.

The results using the VARGOW model with the filter algorithm are shown in Figures 1 thru 3. The results labeled "Actual" are the "actual" data previously discussed. The results labeled "Filtered" are the predicted values for pressure, total gas, and total liquid that were generated by tracking the "noisy" pressure data using the VARGOW model with the filter algorithm. The parameter values in Table 1 were used for this simulation also. 
ACTUAL VS. FILTERED DATA

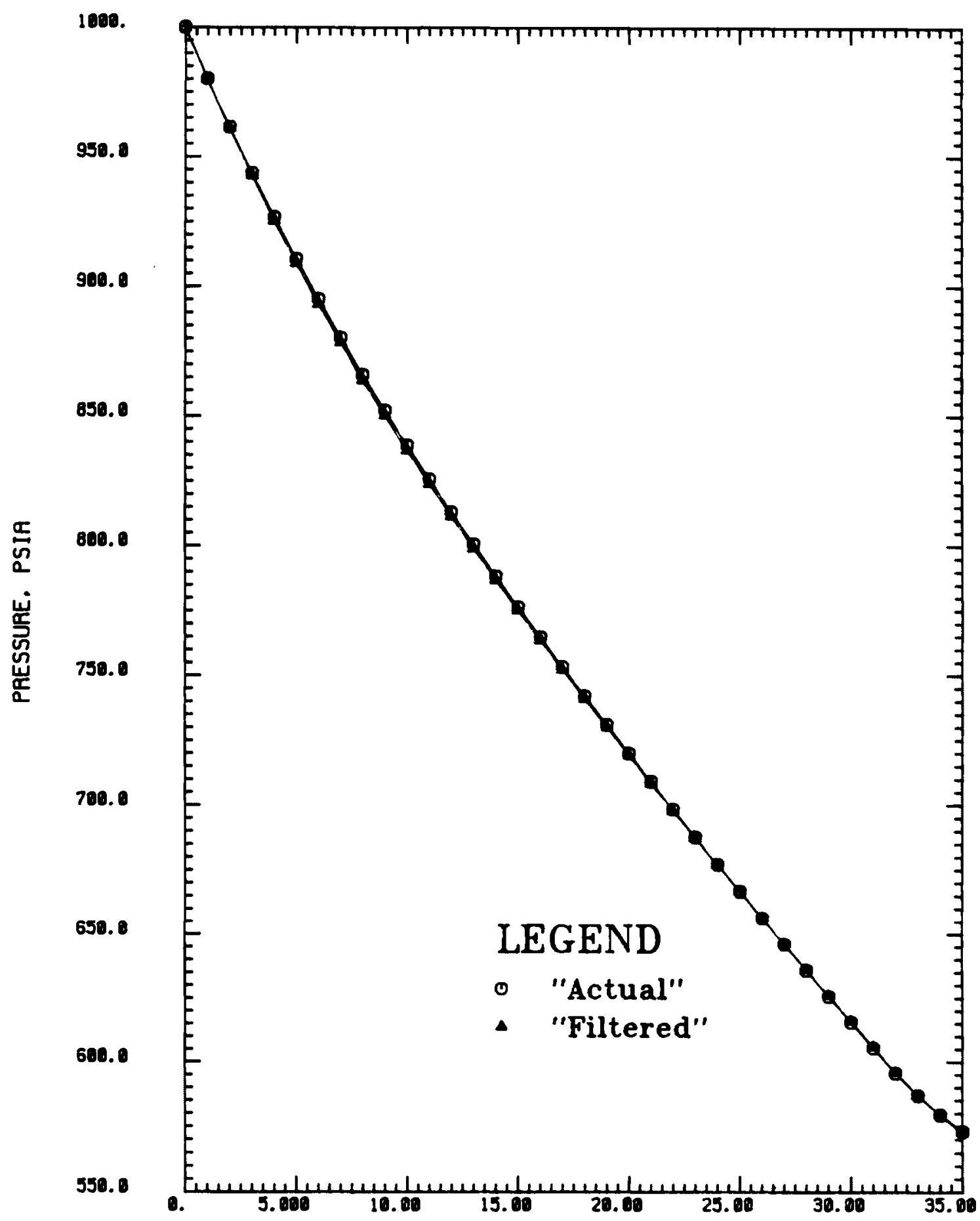

TIME, YEARS

TIME: 09.56:15 DATE $=$ 89-SEP-80

FIGURE 1. Actual Versus Filtered Pressure 


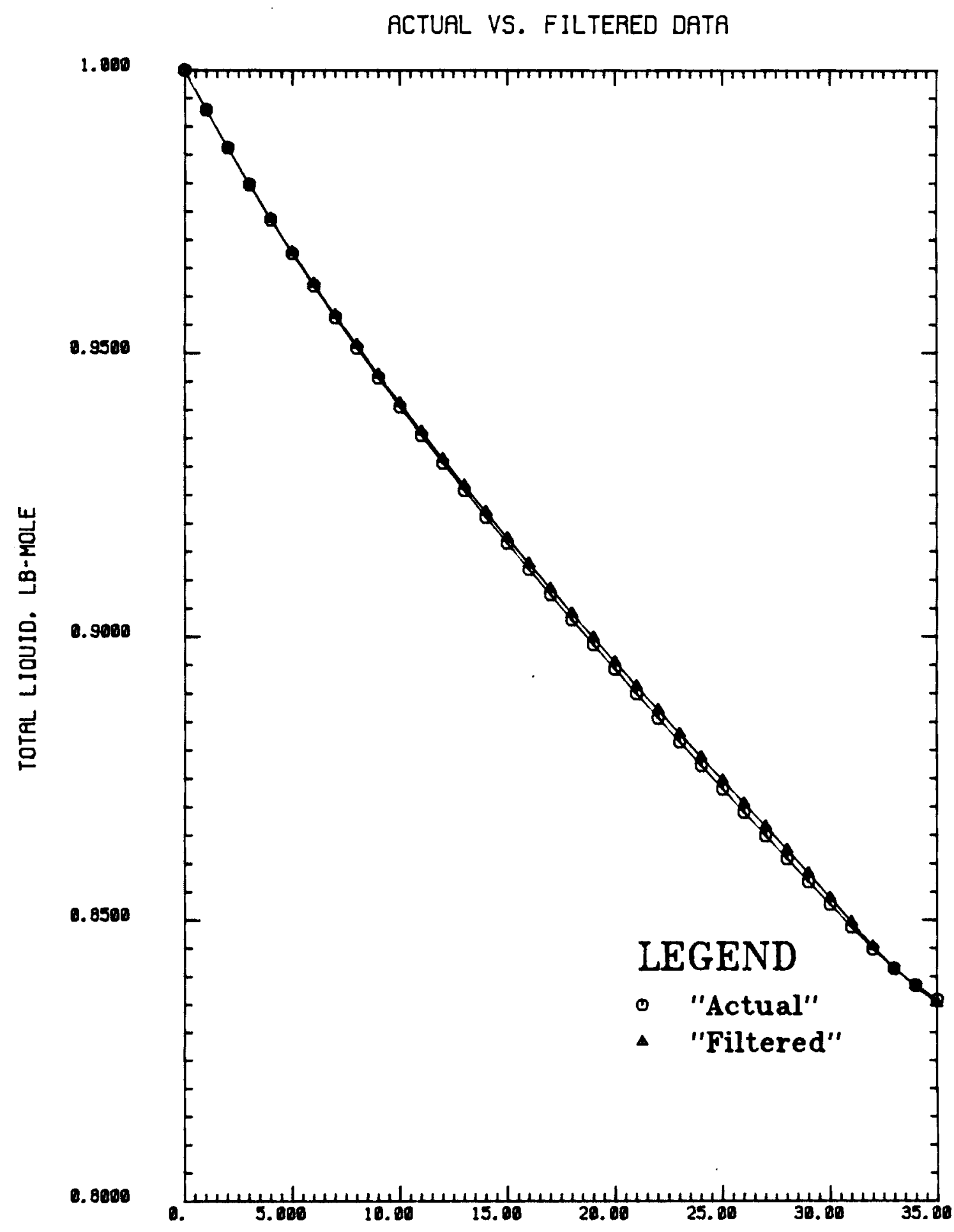

TIME. YEARS

FIGURE 2. Actual Versus Filtered Total Liquid 


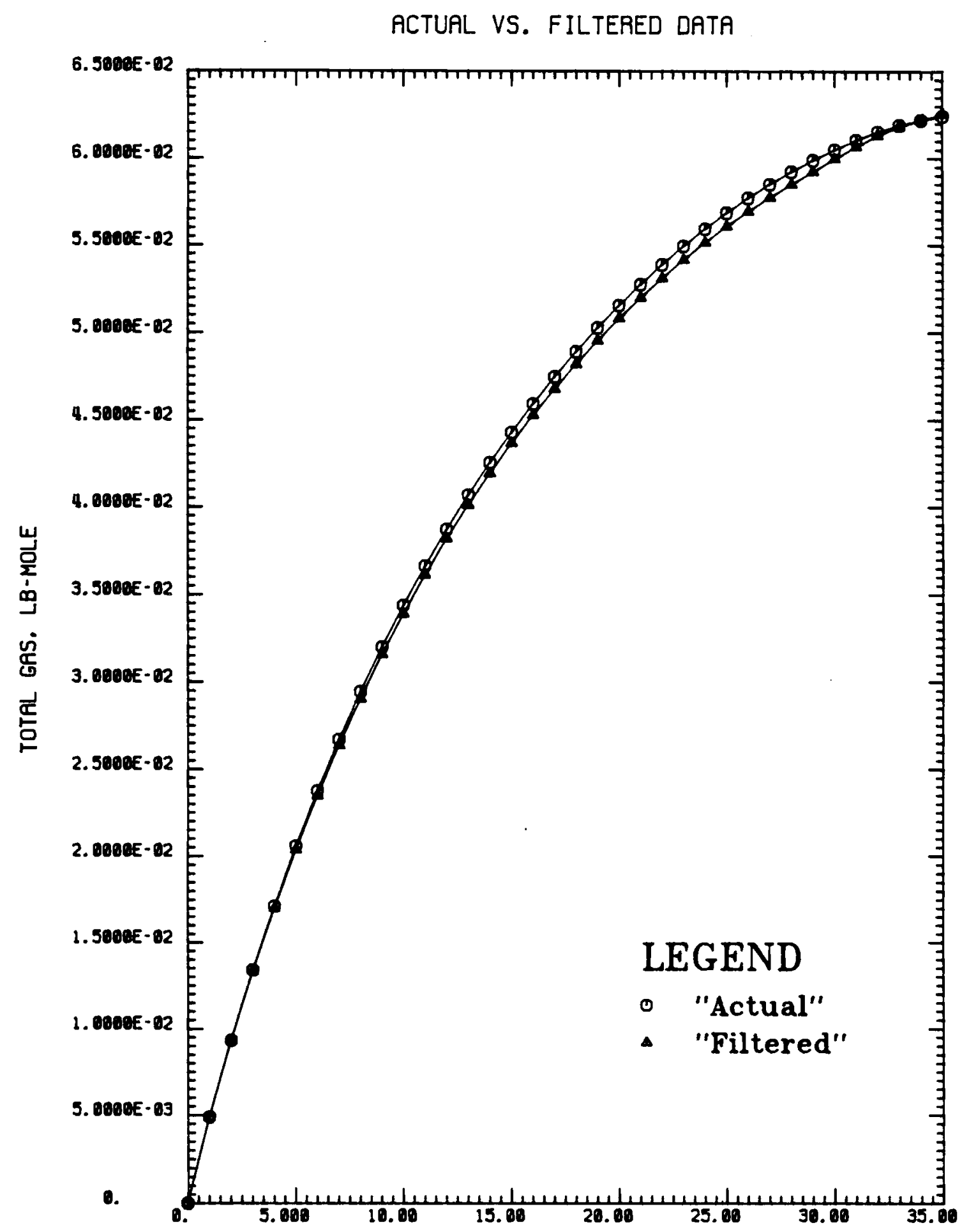

TIME, YEARS

TIME $=09 \cdot 47 \cdot 44$ DATE $=09-$ SEP -80

FIGURE 3. Actual Versus Filtered Total Gas 


\section{REFERENCES}

Bellman, R., Kagiwada, H. Kalaba, R., and Sridhar, R. 1964. Invariant Imbedding and Nonlinear Filtering Theory. RM-4374-PR. RAND Corp. Santa Monica, California.

Kagiwada, H. 1974. System Identification, Methods and Applications, Addison Wes ley, Reading, Massachusetts.

Kalman, R., and Bucy, R. 1961. New Results in Linear Filtering and Prediction Theory, Journal of Basic Engineering Trans. ASME, Series D, Vol 83, No. 1 pp. 95-108.

Lee, E. B. 1968. Quasilinearization and Invariant Imbedding Academic Press, New York.

U.S. Geological Survey, Systems Analysis and Development Section. 1976. A Basic Reservoir Per Se Mathematical Model for Determining Ultimate Recoverry Functions for a Variable Withdrawal Rate of a Gas-0il-Water (VARGOW)

System. SAD Section Report No. 77-10, U.S. Geologica1 Survey, Conservation Division, Lakewood, CO. 
.

. 
APPENDIX

PROGRAM LISTING FOR VARGOW FILTER 


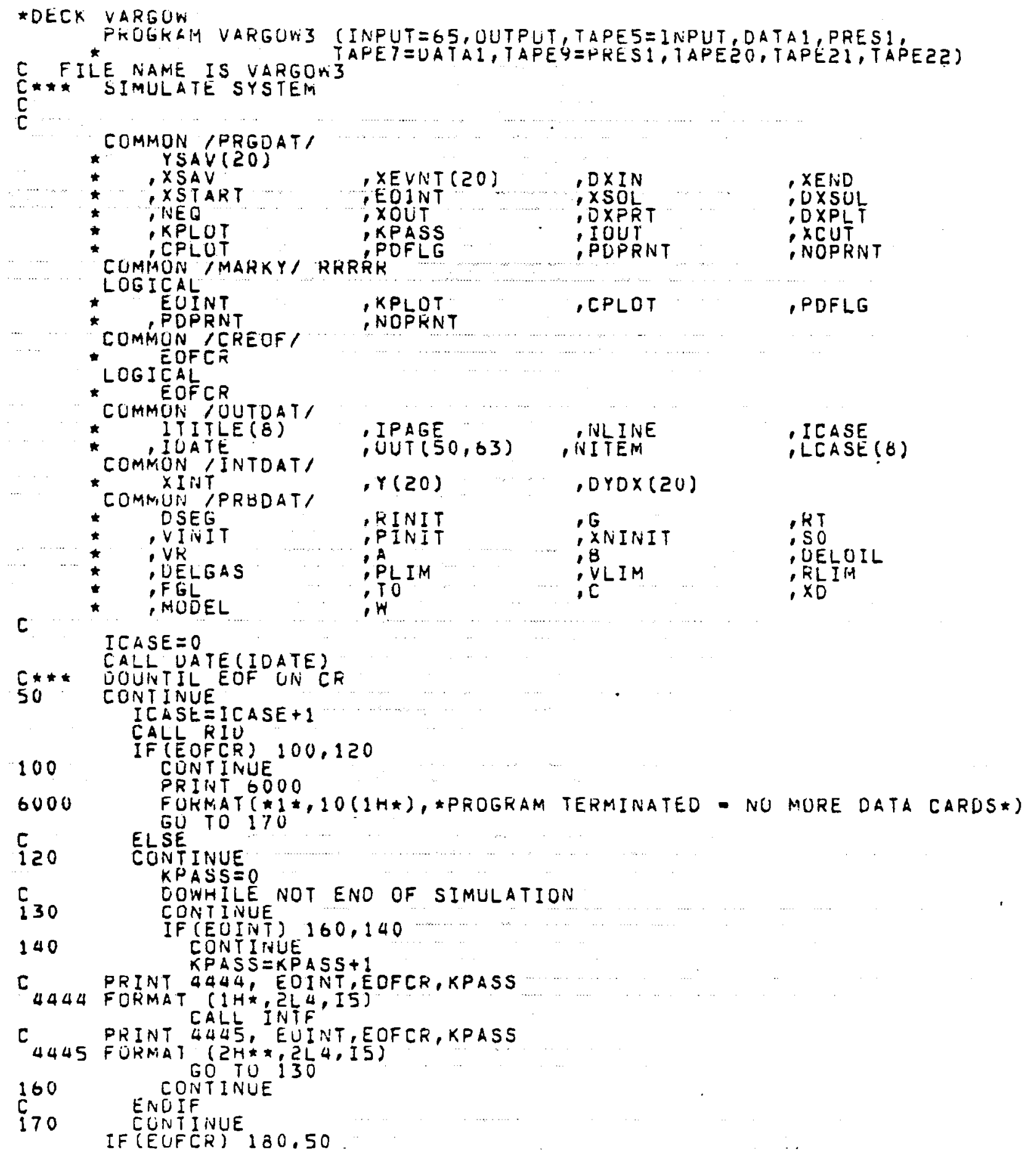

C

ICASE $=0$

C*** CALLUUTIE EIDATE?

SO CONTINUE

ICASE =ICASE+1

CALLRIU

100 IF (EOFCR) 100,120

- IPAGE ,INLINE ICASE

,UUT $(50,63)$,INITEM ,LCASE $(8)$

,$Y(20) \quad$,OYOX(20)

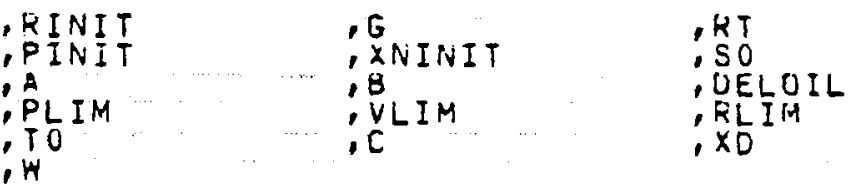

6000 FUKNAT $\$ 1 *, 10(1 H *)$, \#PROGRAM TERMINATED - NU MURE DATA CARDS*)

I $20 \quad$ ELSE

CONTINUE

130 OOWHILE NOT ENO OF SIMULATION

140 IF (EUINT) 160,140

KPASS=KPASS+1

C PRINT 4444 , EOINT,EDFCR,KPASS

4444 FORMAT ( $1 H \star$ I ILL , IS)

C PRINT 4445, EUINT,EOFCR, KPASS

4445 FURMAT (2H**:2L4, IS)

160 ENOIFTINUE

I70 IF ENNTINUE 180.50 


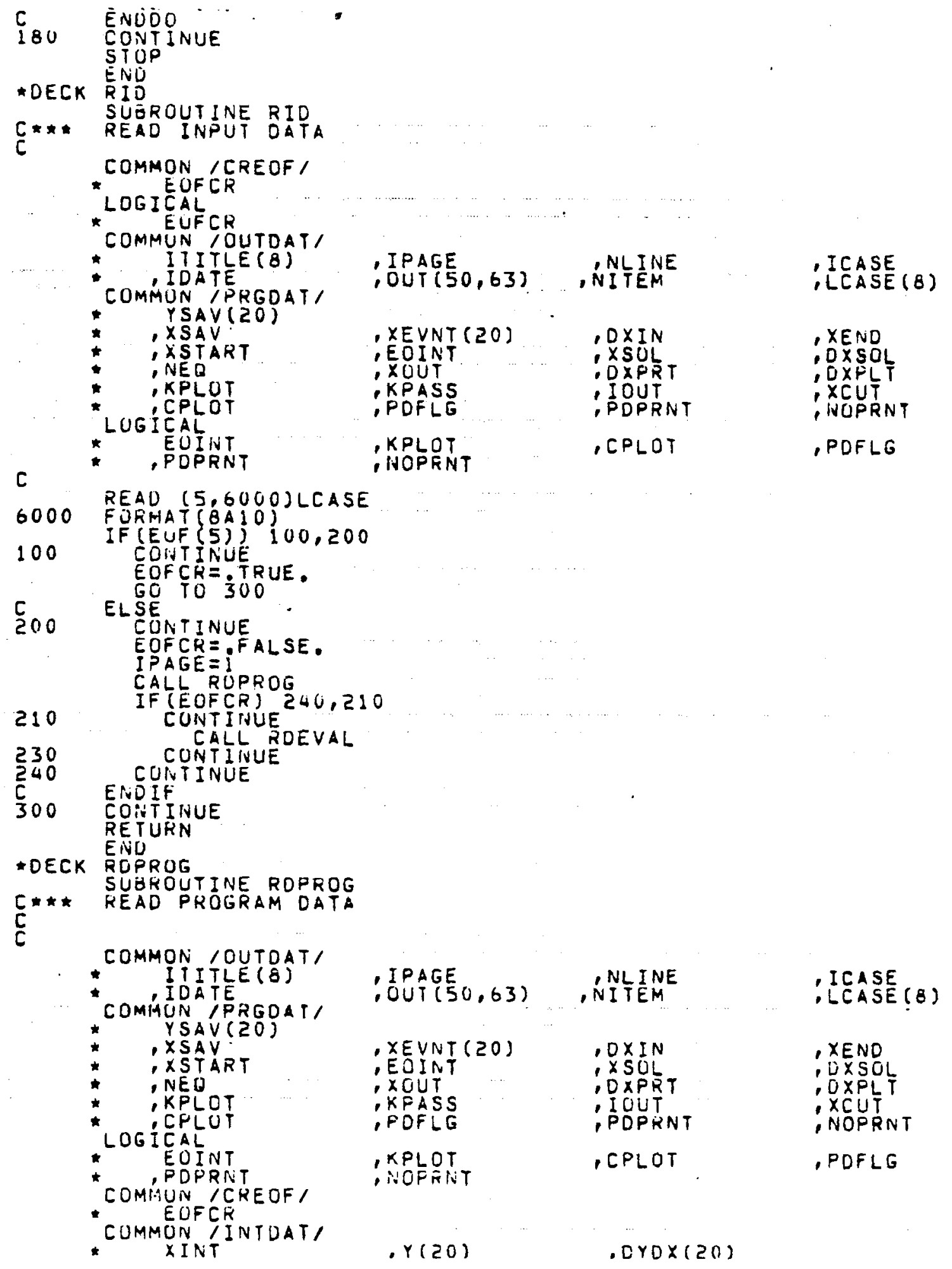




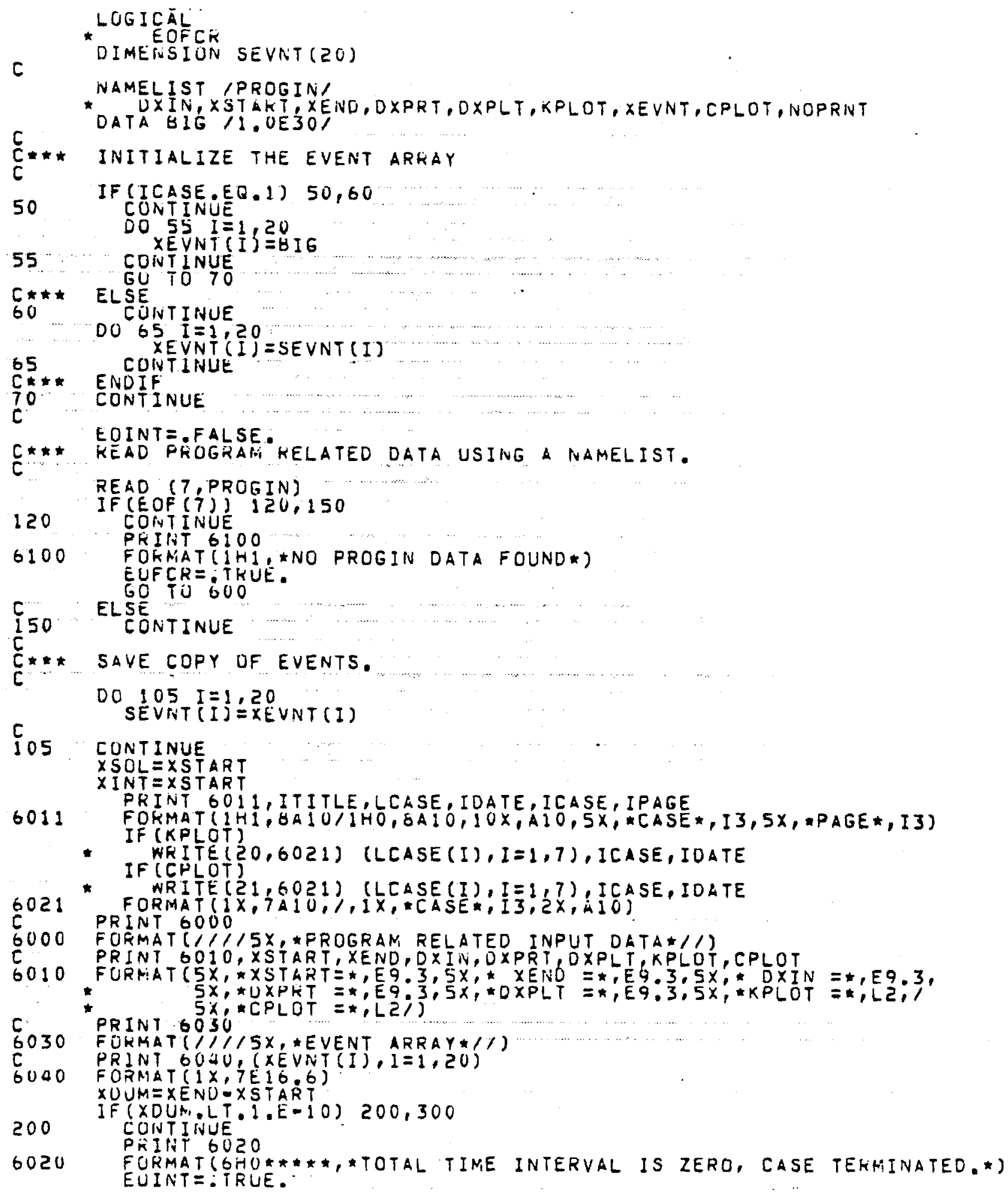




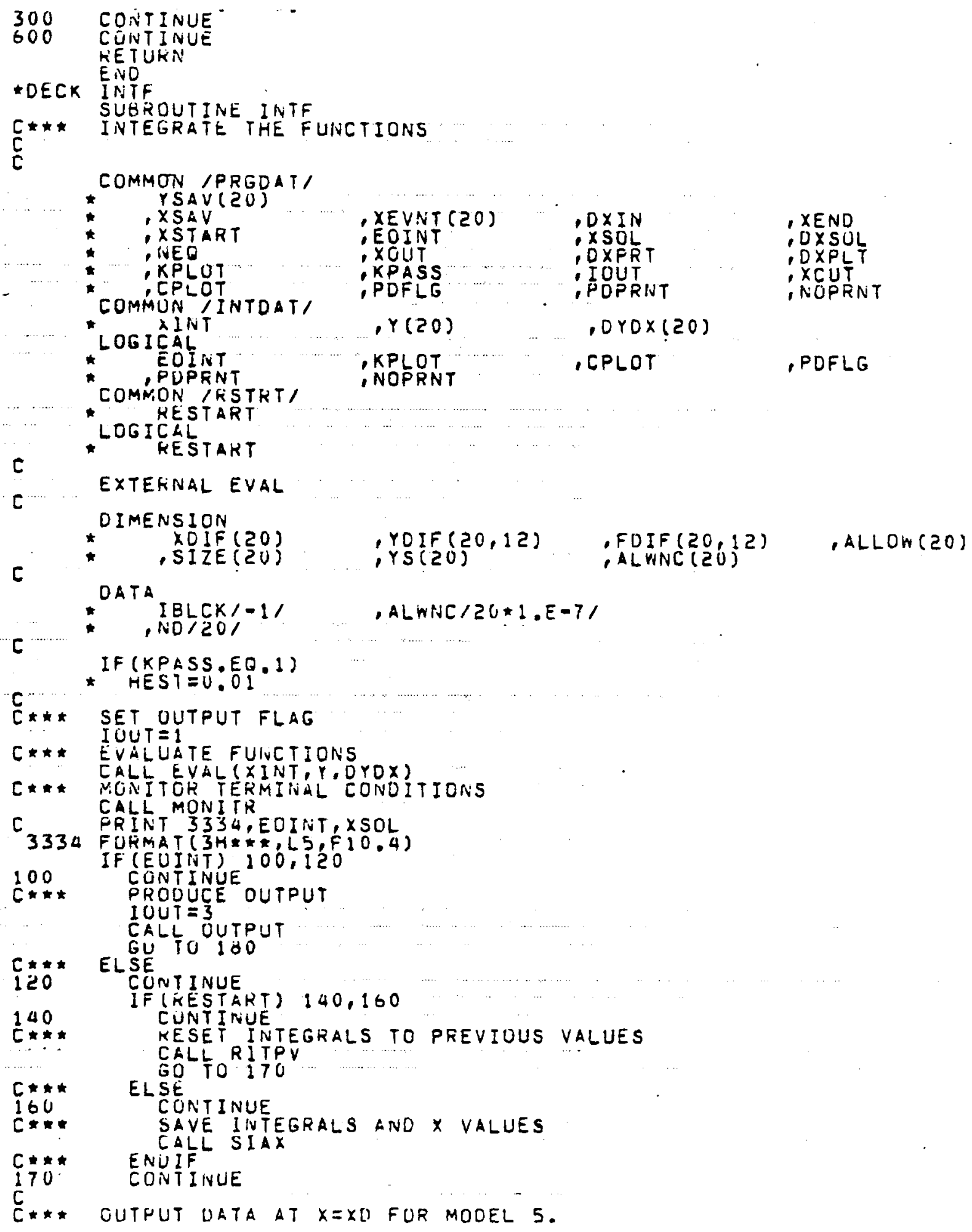




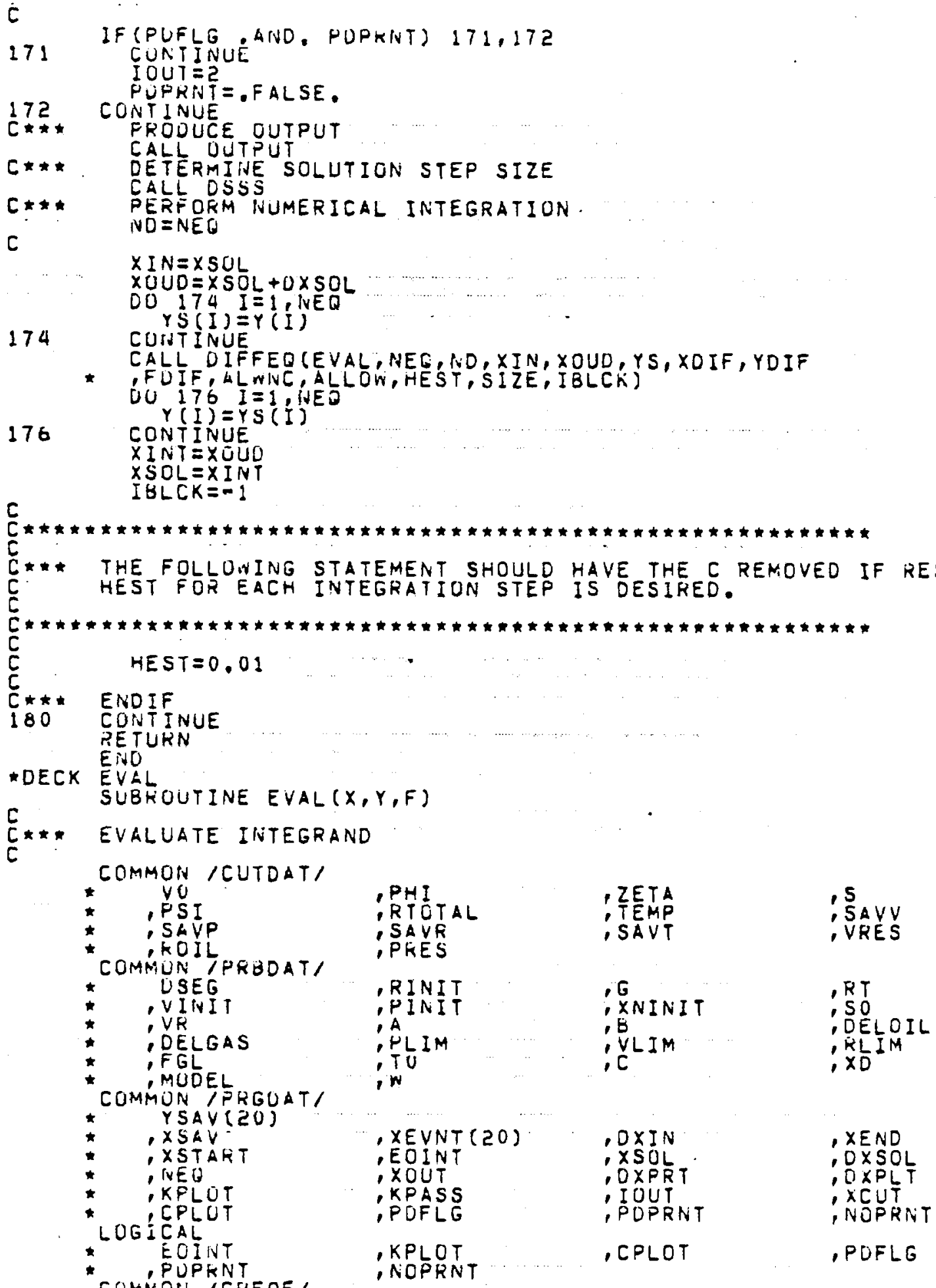

$c$
$C$
$C$
$C$
$C$
$C$
$C$
1
$c$
$c$
$c$
$c$

C ${ }^{C} *$ EVALUATE INTEGRAND

common /CUTDat/

- PHI

- RTótal

- SAVF

pREs

, ZETA

.5 5 AVV

, RINIT

,PINIT

, HLIM

, TLIM

w

, SAVT

IRES

, XEVNT $(20)$

- EOINT

- XOUT

KPASS

, POFLG

,$G$

XNINIT

VLIM

RT
SO

- DELOIL

- RLIM

, KPLOT

, NOPRNT

, XEND

DXSOL

, OXPL

- XCUT

NOPRNT

I POPRNT

- POFLG 


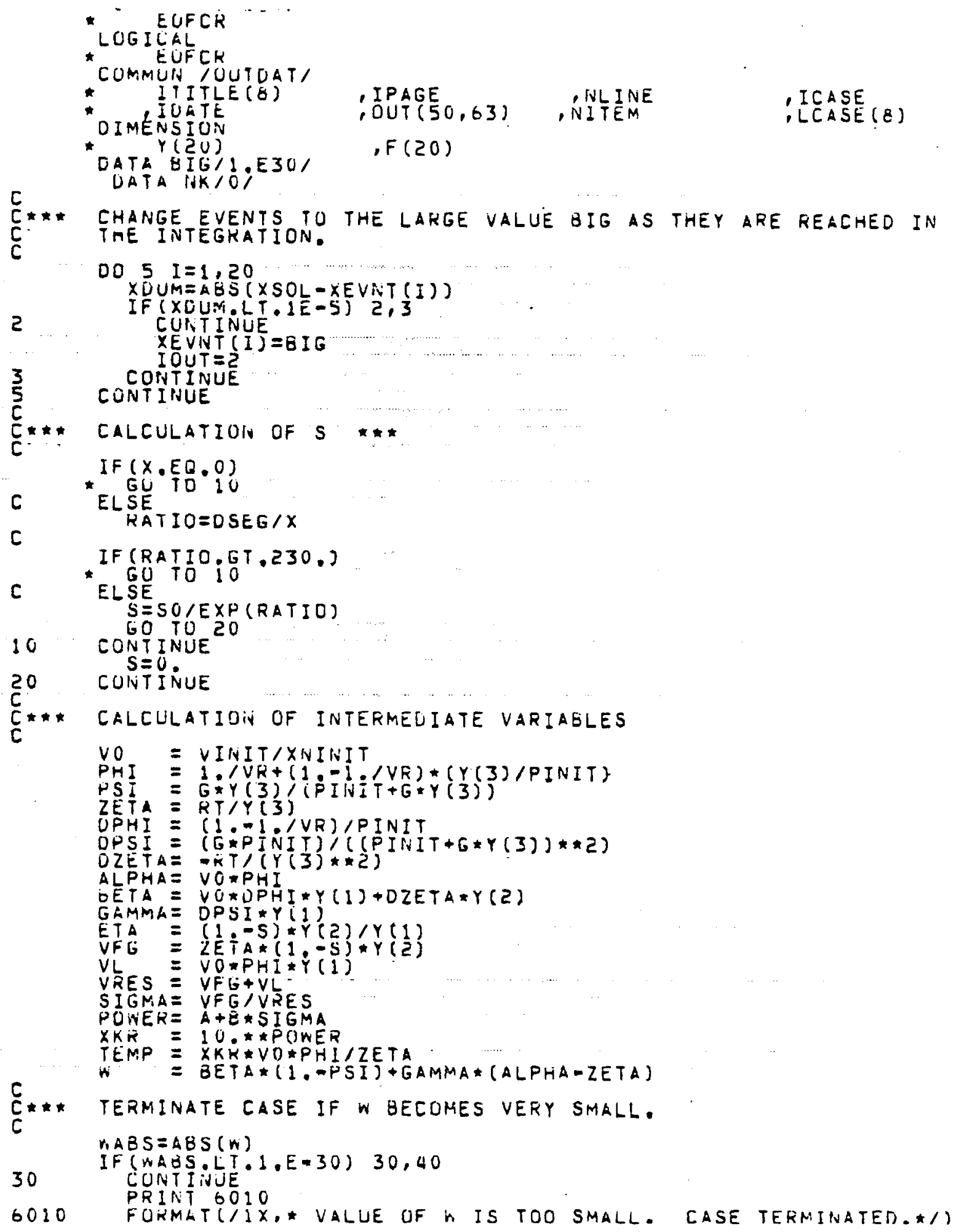




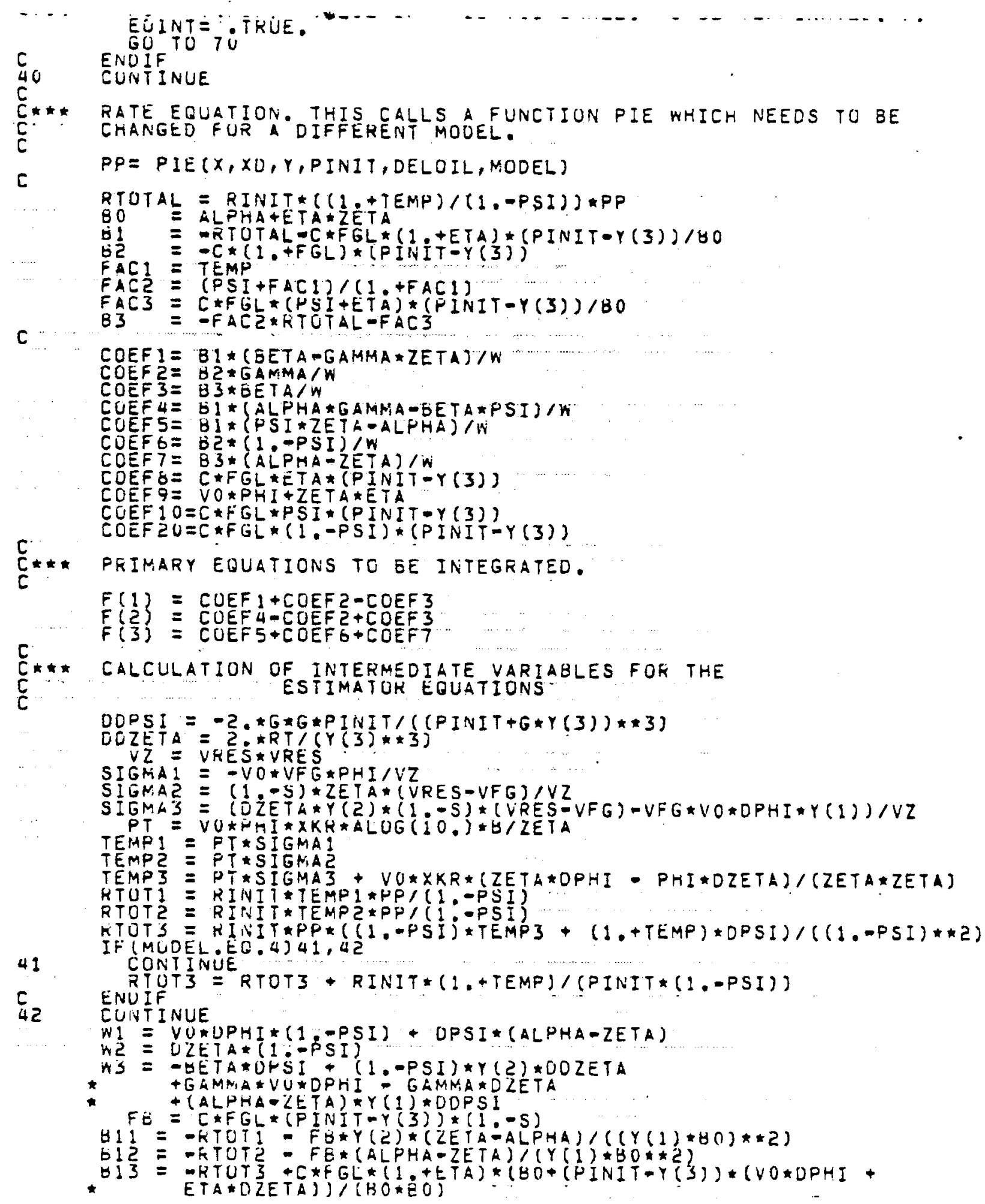




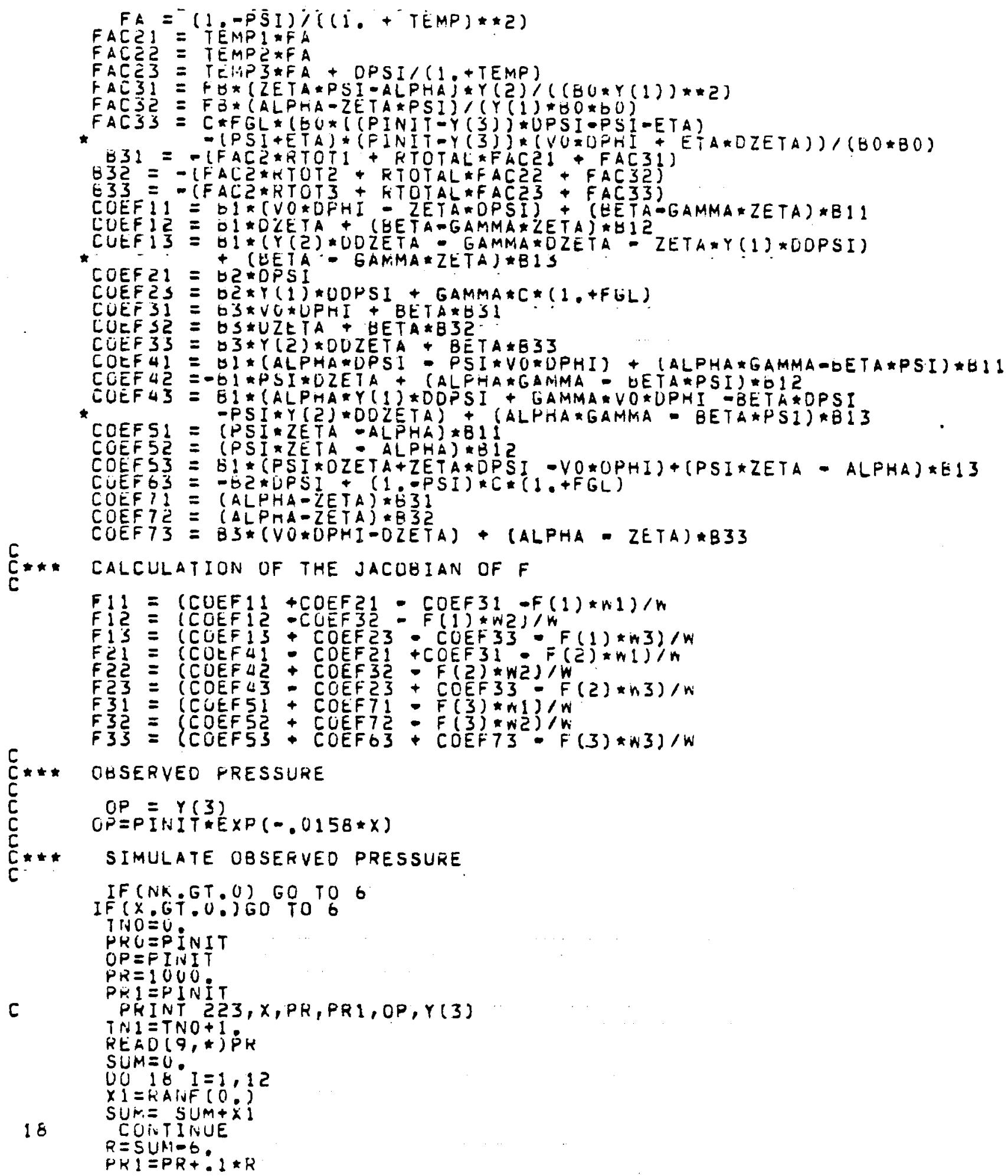




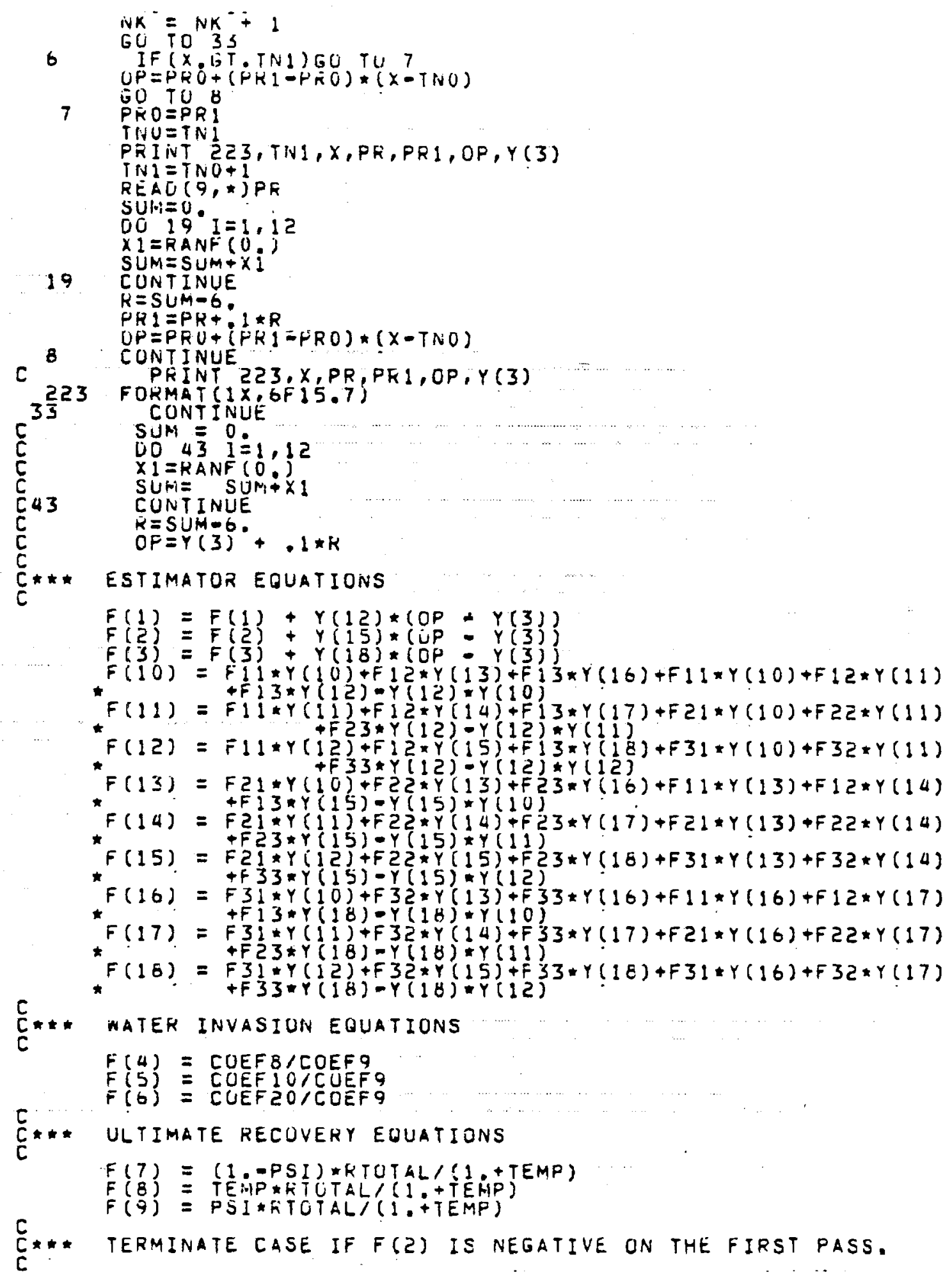




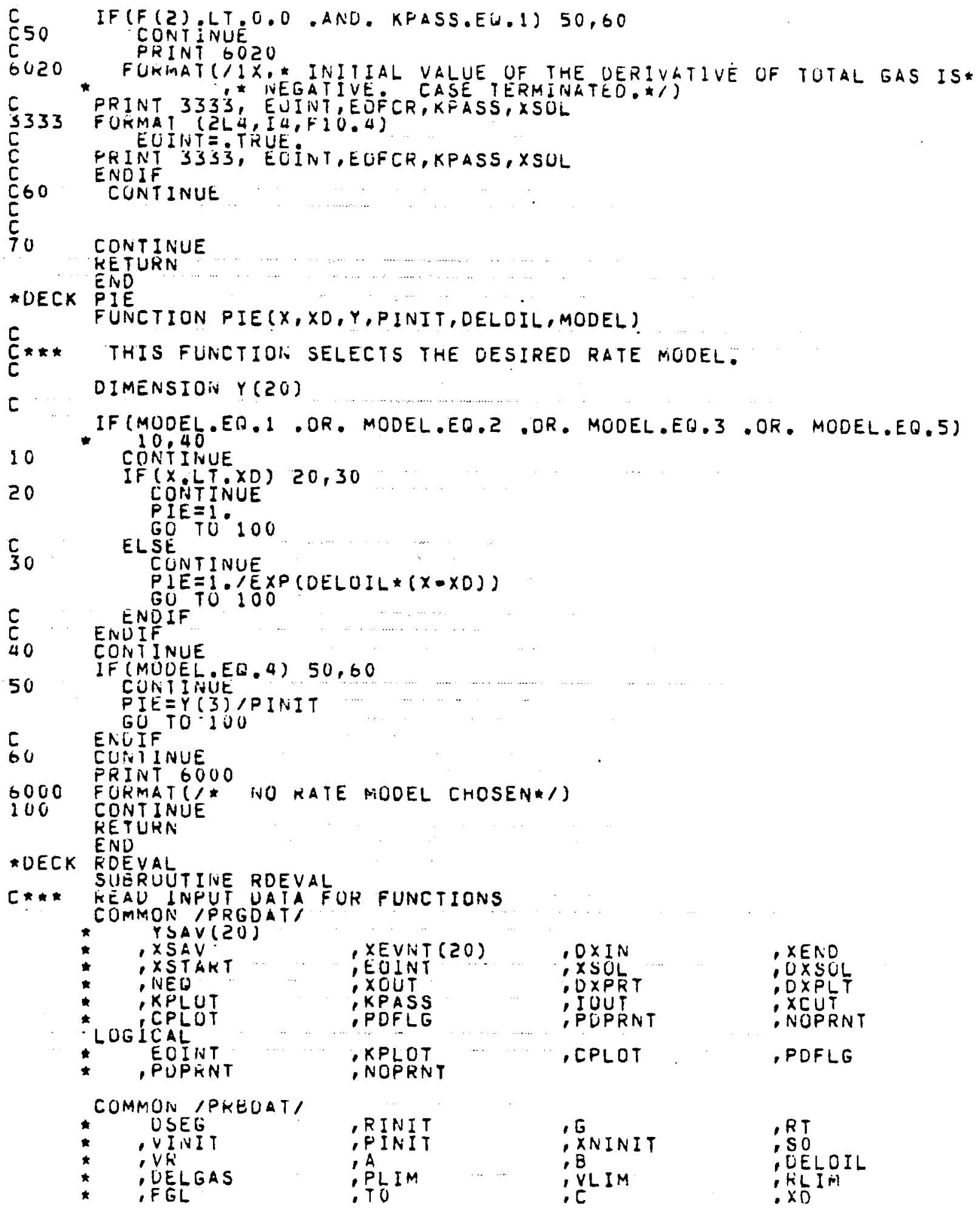

\begin{tabular}{|c|c|c|}
\hline $\begin{array}{l}\text { RINIT } \\
\text { PINIT } \\
\text { A } \\
\text { PLIM } \\
\text { TL }\end{array}$ & $\ldots \quad \ldots$ & $\begin{array}{l}\text { : } X N \text { INIT } \\
\text { : } \\
\text { : ELIM }\end{array}$ \\
\hline
\end{tabular}

, PDFLG 


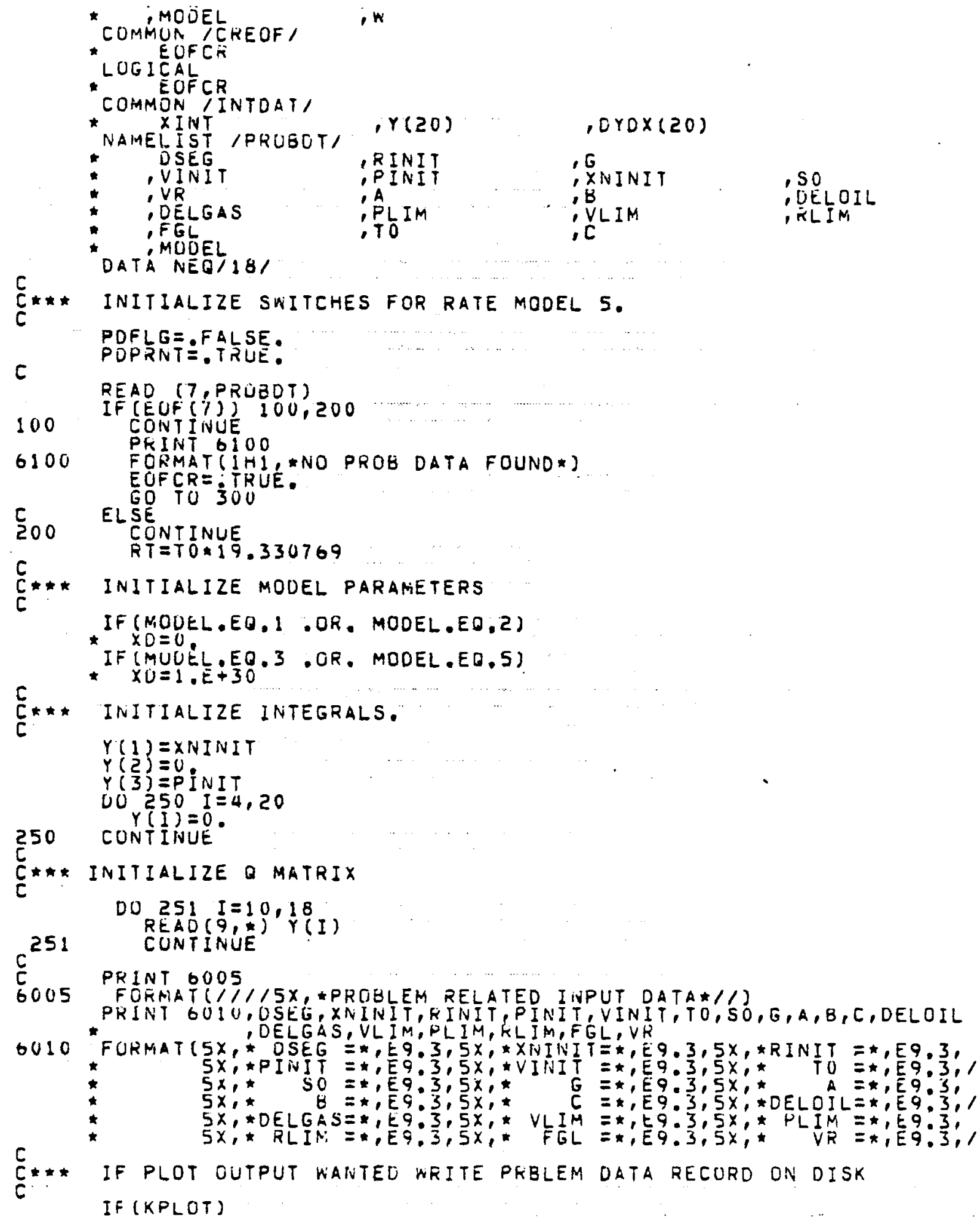




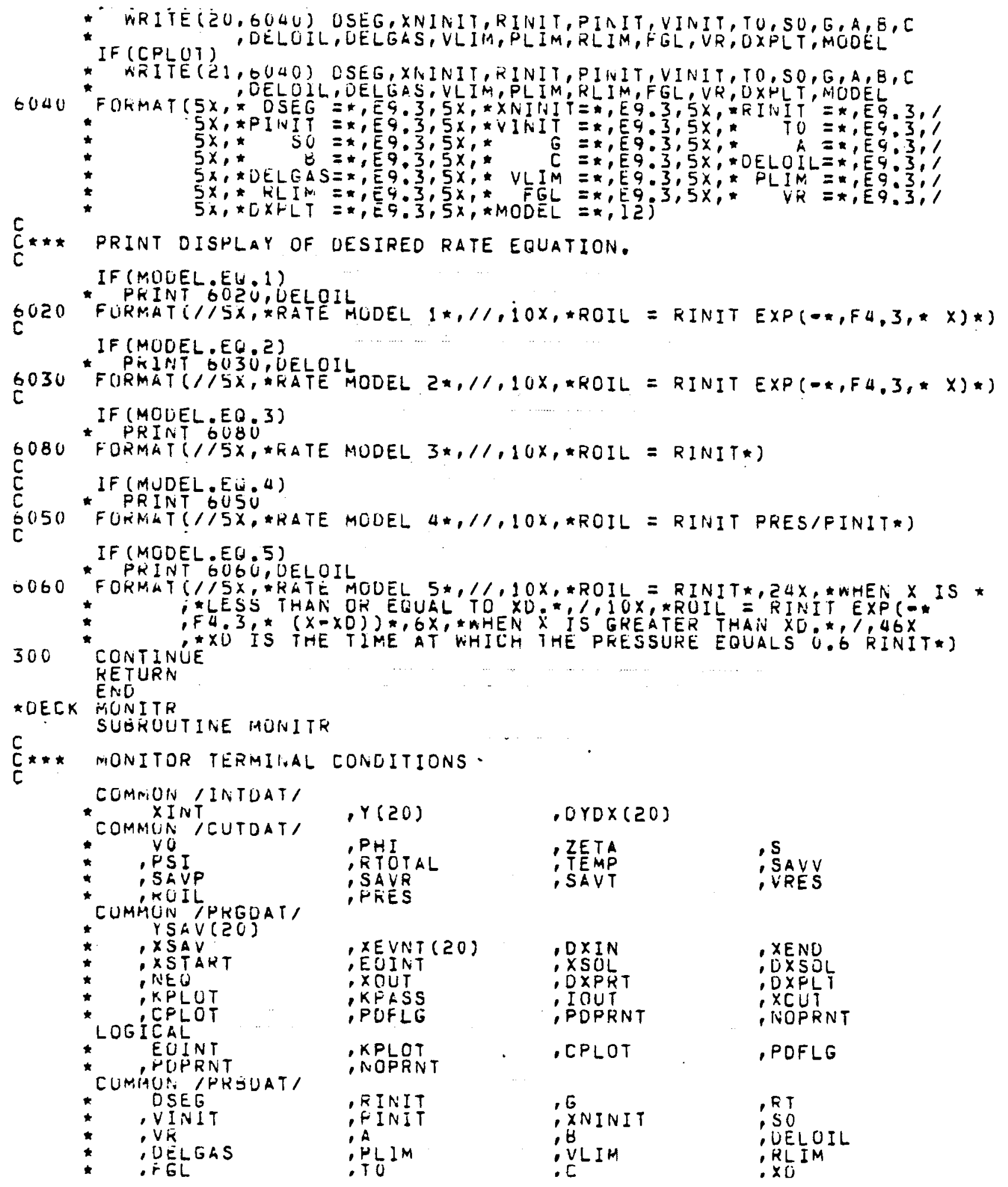




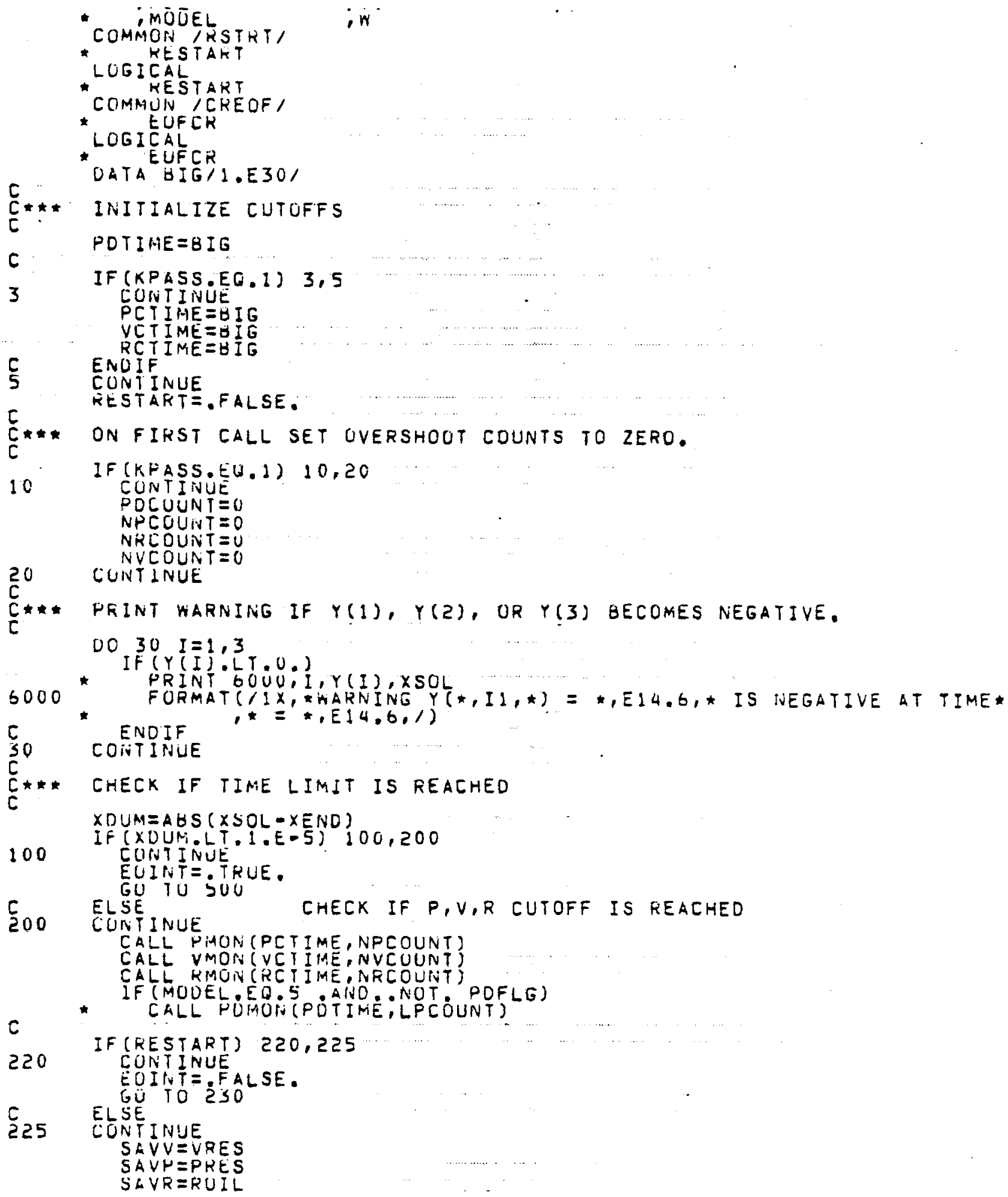




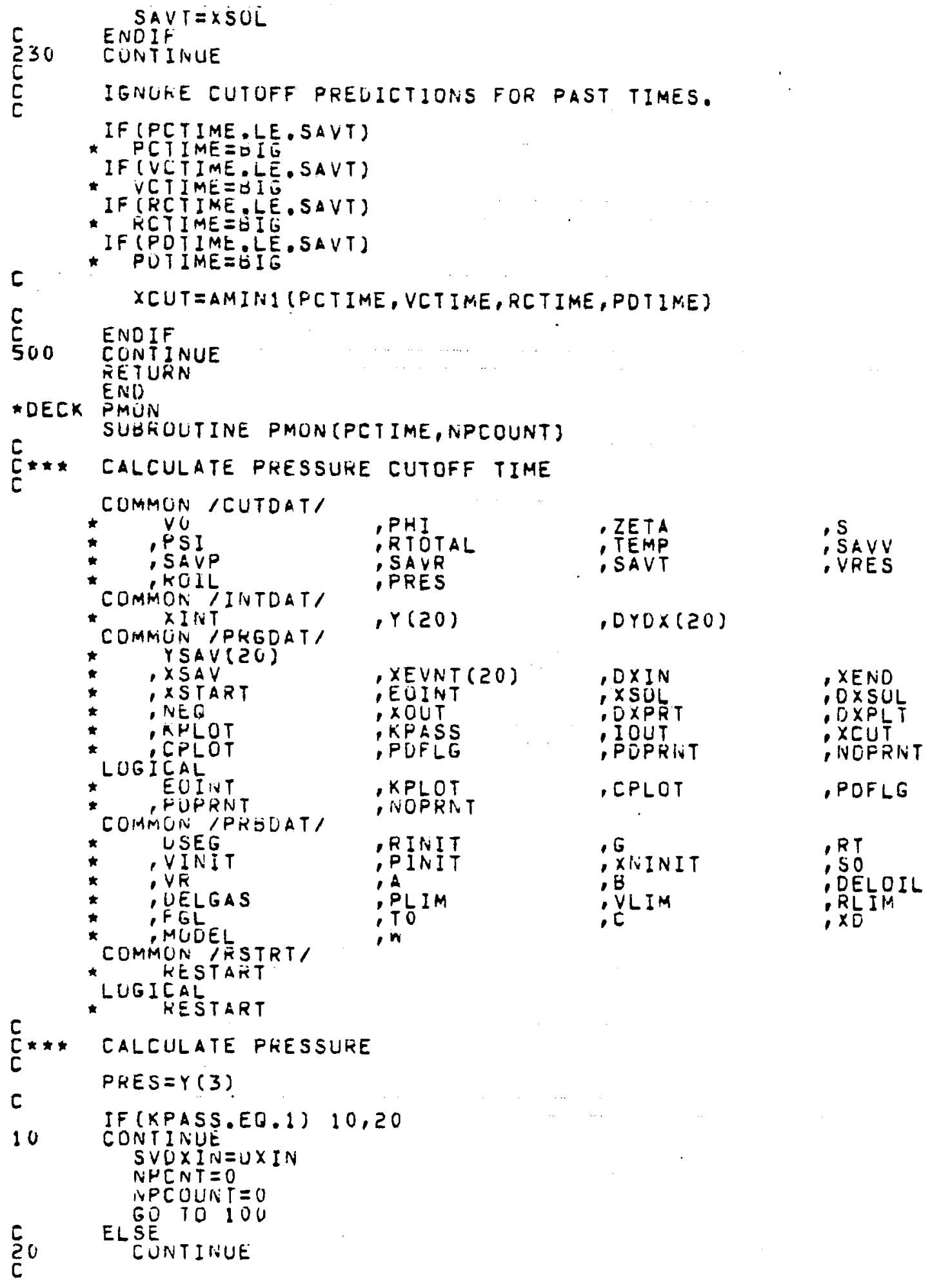




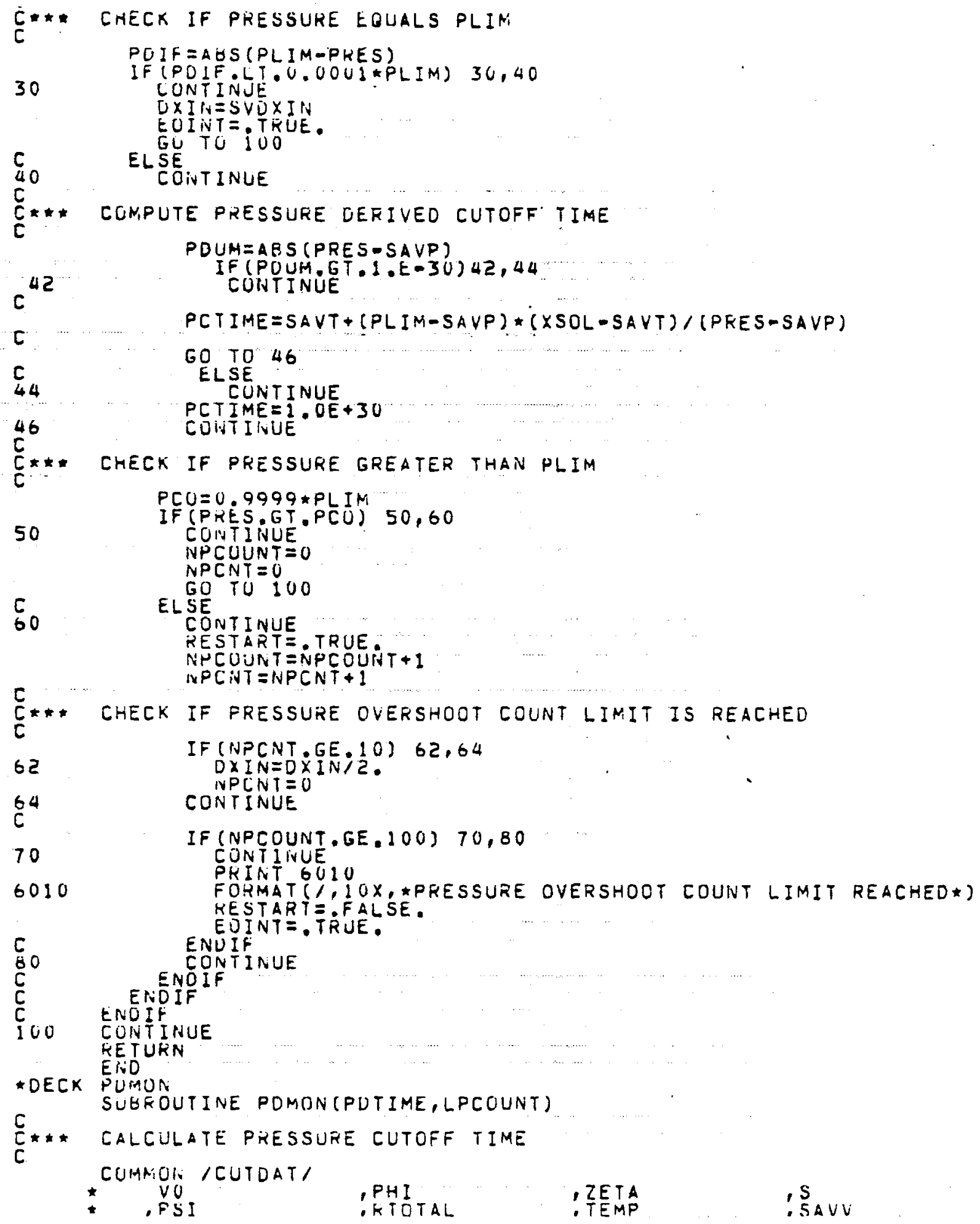




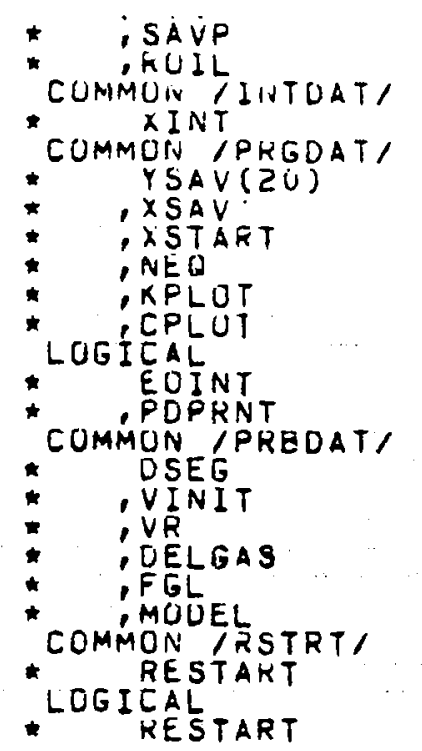

\begin{tabular}{|c|c|c|c|}
\hline $\begin{array}{l}\text { :SAV̈K } \\
\text {, PKES }\end{array}$ & ; SĀVT & & $\because \overline{V R E} \dot{S}$ \\
\hline,$y(20)$ & , OYOX $(20)$ & $\cdot$ & \\
\hline $\begin{array}{l}\text { XEVNT }(20) \\
\text {, EOINT } \\
\text { XOUT } \\
\text { KPASS } \\
\text {, POFLG }\end{array}$ & $\begin{array}{l}\text { OXIN } \\
\text { XSOL } \\
\text { OXPRT } \\
\text { IOUT } \\
\text { PUPRNT }\end{array}$ & & $\begin{array}{l}\text { XENO } \\
\text { OXSOL } \\
\text { OXPLT } \\
\text { XCUT } \\
\text { ONOPRNT }\end{array}$ \\
\hline $\begin{array}{l}\text { KPLOT } \\
\text { NOPRNT }\end{array}$ & , CPLOT & & ,POFLG \\
\hline $\begin{array}{l}\text { RINIT } \\
\text { :PINIT } \\
\text { PA } \\
\text { PLIM } \\
\text { TUU } \\
\text { in }\end{array}$ & $\begin{array}{l}\text { G } \\
X N I N I T \\
B V L I M \\
, C\end{array}$ & & 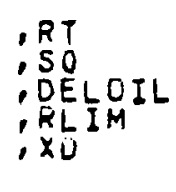 \\
\hline
\end{tabular}

$\stackrel{C}{C} * * *^{C}$

CALCULATE PRESSURE

PRES $=Y(3)$

C PUE

10 IF (KPASS.EO.1) 10,20

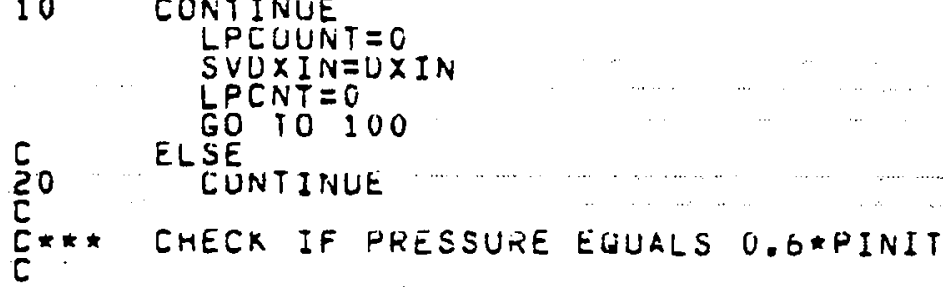

PUIF = AES (PL-PRES) $30 \quad$ IF (PDIF.LT.0.00U06*PINIT) 30,40 UXIN = SVDXIN PUFLEE TRUE. $X D=X S O L$

CO ELSERTINUE

C.* COMPUTE PRESSURE UERIVEO CUTOFF IIME PDUUMEABS (PRES-SAYP)

IF (FUOUM, GT, I. E- 30) 42, 44

42 CONTIIVUE

C PDTIME $=S A V T+(F D-S A V F) *(X S O L-S A V T) /(P R E S-S A V P)$

C GO TO 46

$44 \quad P C T I M E=1 . O E+30$

46 CHECK CONTINUE

C*\# CHECK IF PRESSURE GREATER THAN PD 


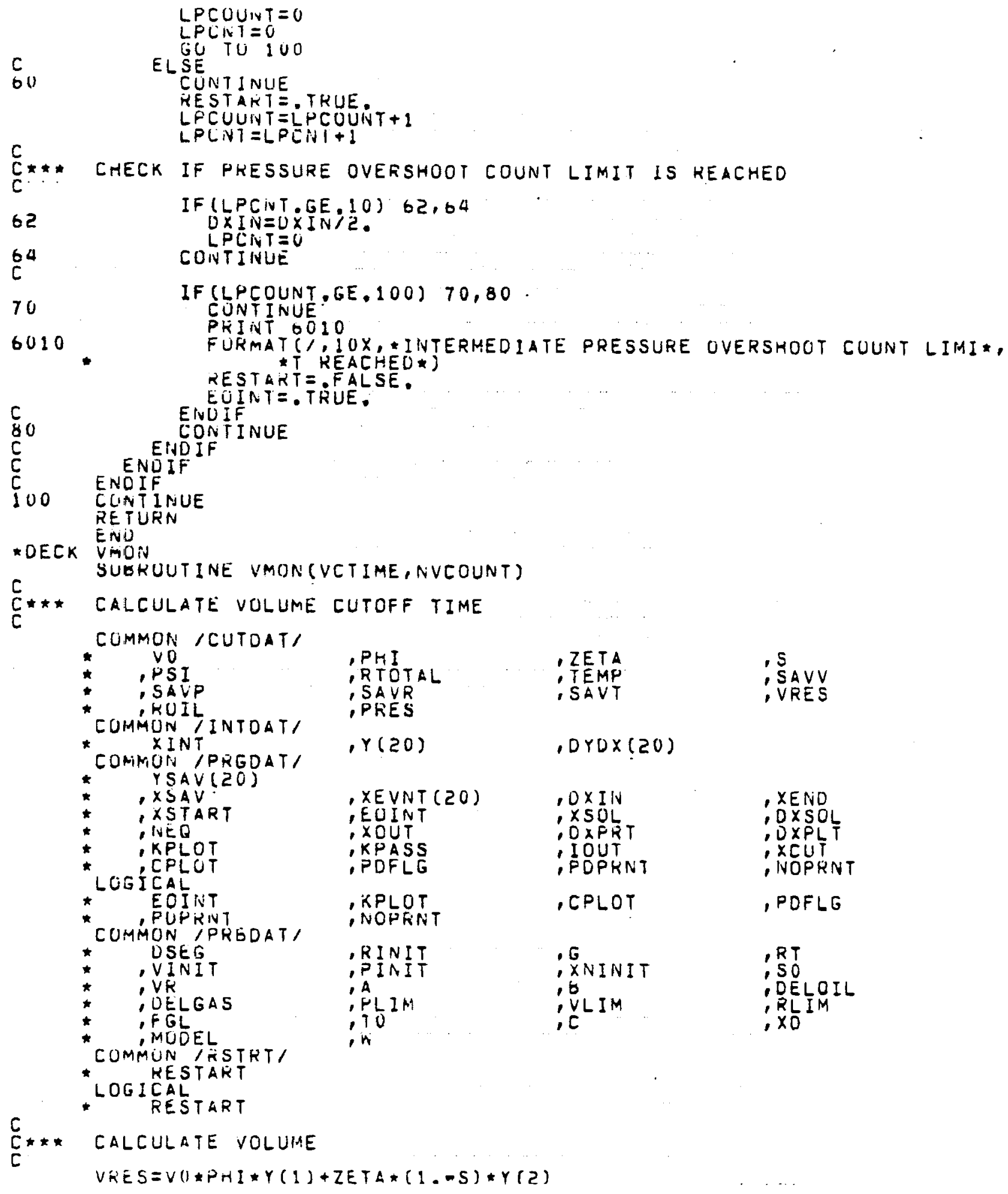




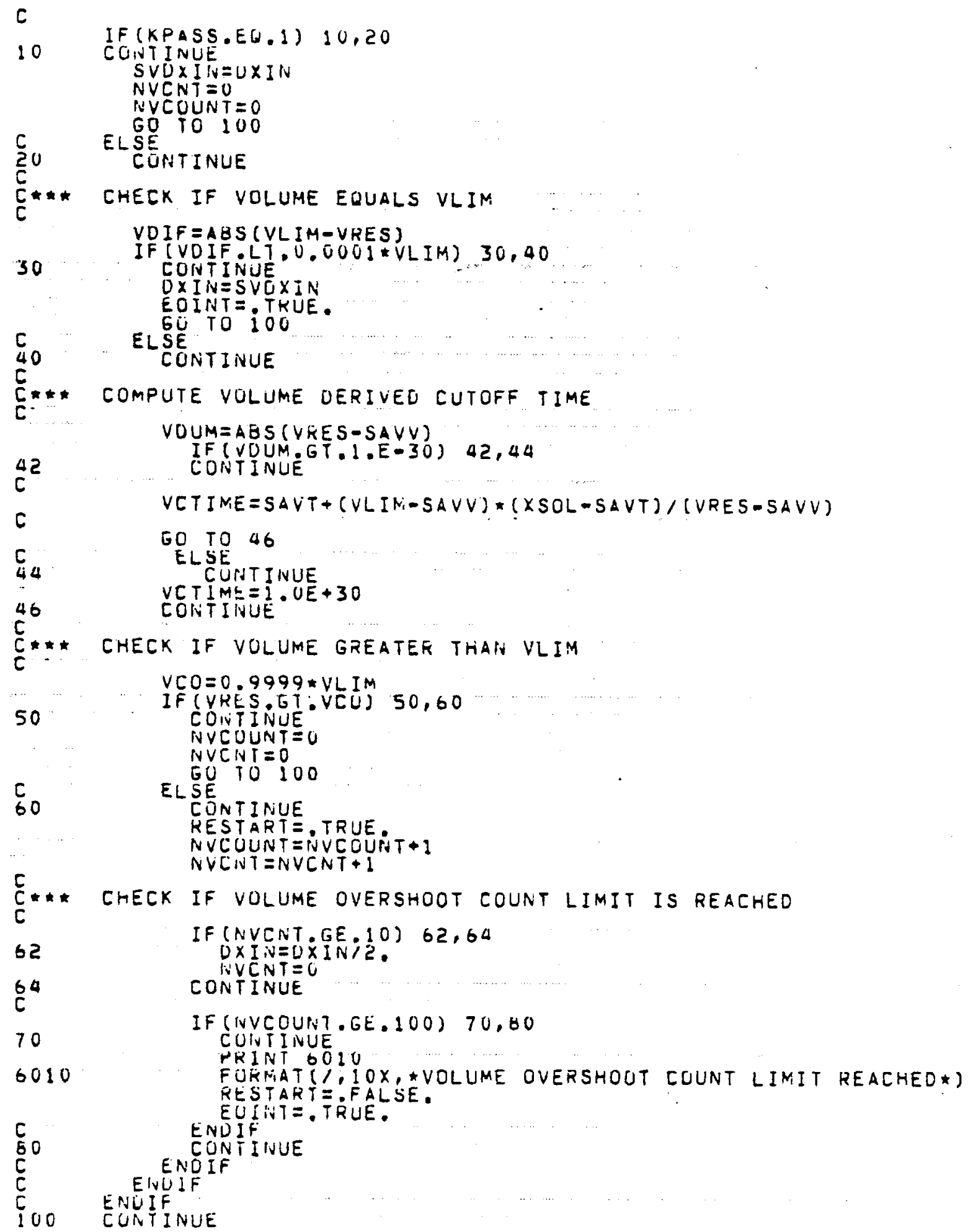




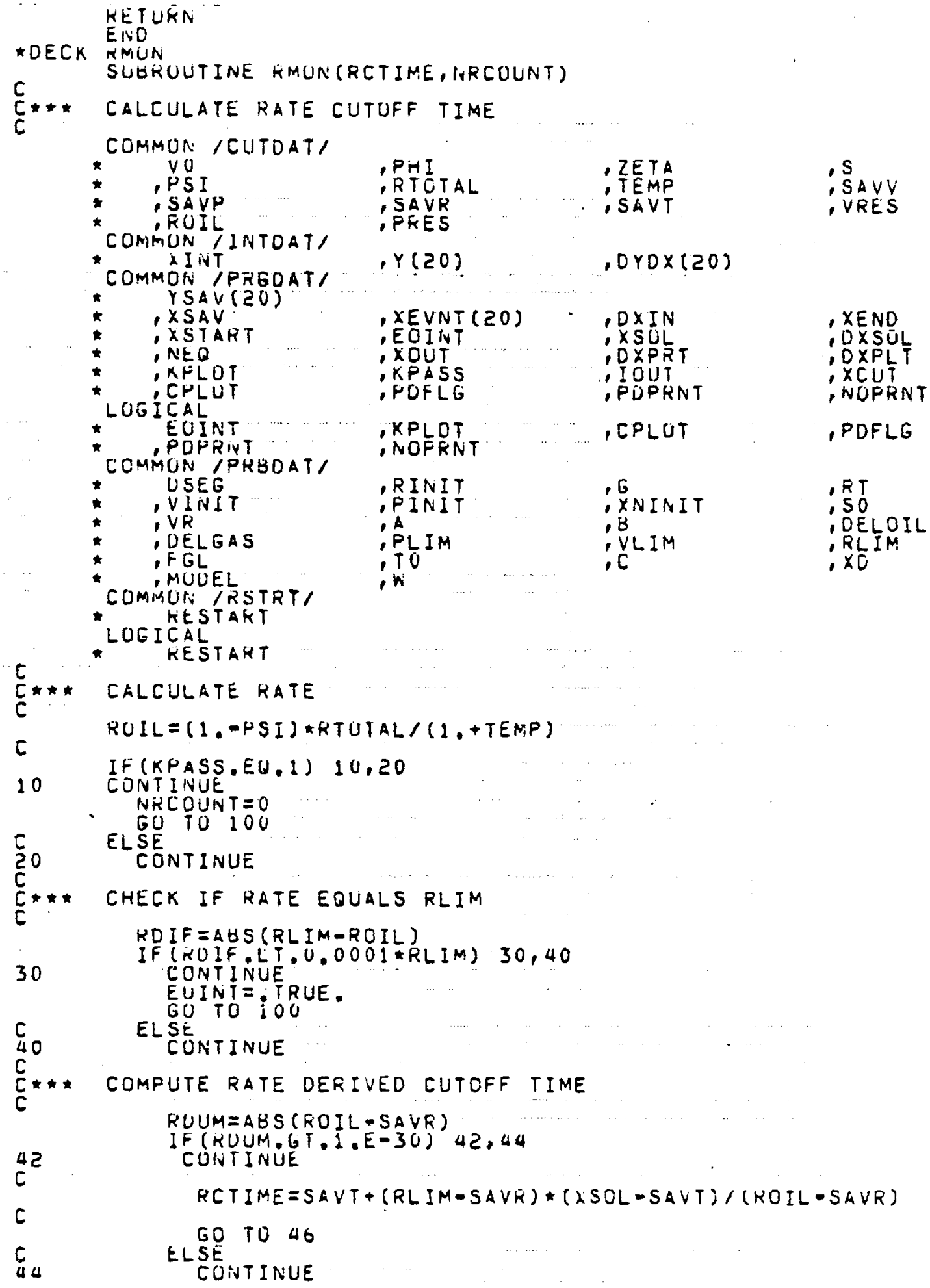

44 CONTINUE 


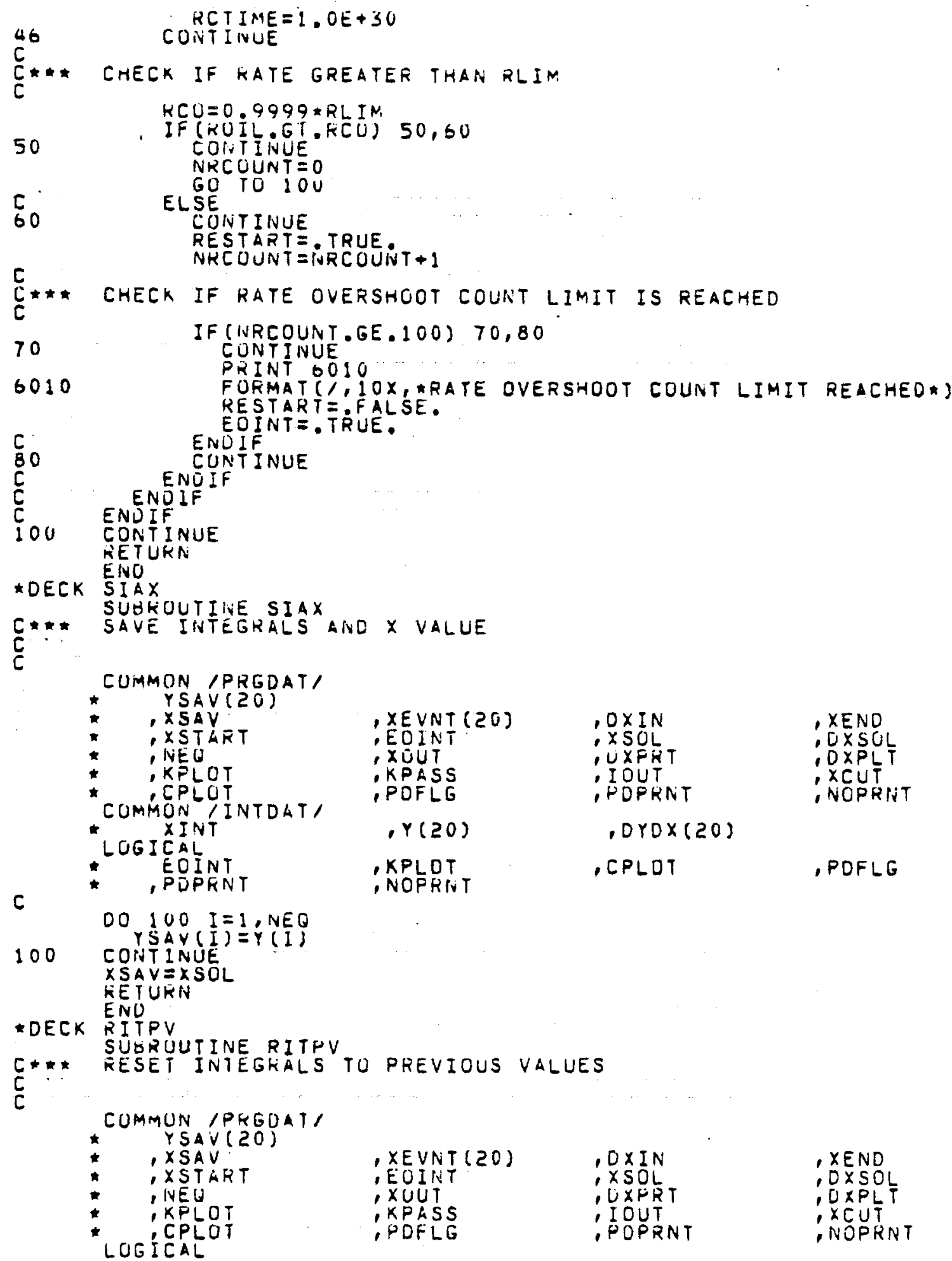

- XEVNT (20) - EOINT , XUUT -KPASS -POFLG ,$Y(20)$

- KPLDT - NOPRINT

, OXIN , XSOL I UXFET - IOUT 
C

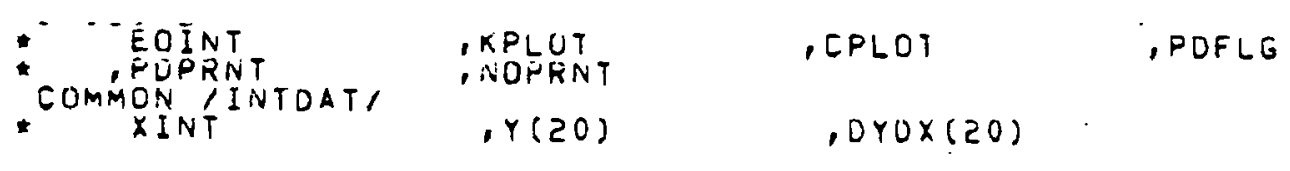

Y

CONTINUE

XINT $=X S A V$

$X S U L=X S A V$

RETURN

×DECK OSSS

SUBROUTIINE DSSS

C*** OETERMIINE SOLUTIUN STEP SIZE

c

*OMMON IPEgDat'
YSAVGZOT

- XSAV

- XSTART

- MEQ

- KPLUT

- logícal

* EUINT

DATÁ BIEII.EIO/

\begin{tabular}{|c|c|}
\hline $\begin{array}{l}\text { XEVNT }(20) \\
\text { XOINT } \\
\text { XOUT } \\
\text { XPASS } \\
\text { XOFLG }\end{array}$ & $\begin{array}{l}\text { OXIN } \\
\text { XXOL } \\
\text { :OXPRT } \\
\text { IOUUT } \\
\text { POPRNT }\end{array}$ \\
\hline $\begin{array}{l}\text { KPLOT } \\
\text { NOPRN }\end{array}$ & , CPLOT \\
\hline
\end{tabular}

- XENT

, UXSOL

, XXPLT

, XCUT

-NUPRRT

C

IF (KPASS.EO.1) KNTZFO=0

$D X M I N=B I G$

UO $100 \quad I=1,20$

DX XXEVNT'( I) - XSOL

100 CONTINUE

DXENE $=\sum E N D-X S O L$

$D \times O U T=X \cup \cup T-X S O L$

UXCUT $=X C U T-X S O L$

C. UXSOL =AMINI (DXMIN, OXENO, OXOUT, DXIN, DXCUT)

200

IF (OXSOLLT. 1.E-5) 200,300

KNTZHOEKNTZRO+

IF (KNTZKD.GE.3) 220,240

220 CONTINUE

PRINT 6000,DXEND,OXOUT, DXMIN, XSOL, XEVNT

6000

FORMAT (IH), INTEGRATIOH STEP IS ZERO\#

IHO, DXEND $=*, E ! 2.6 /$

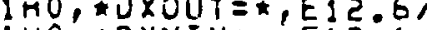

IHO, DXMIN $= \pm, E I Z .6 /$

$1 H O, * X S O L=\star, E I 2.61$

IHO EEVEIT ARRAY*

UINT $=$ THUE

TRUÉ.

200 CUNTINUE

C. ELSE

0 TO 320

300

CONTINUE

320 CONTINUE

RETURN

END

- DECK OUTPUT

SUBRDUTINE OUTPUT

C** PROUUCE OUTPUT

C 


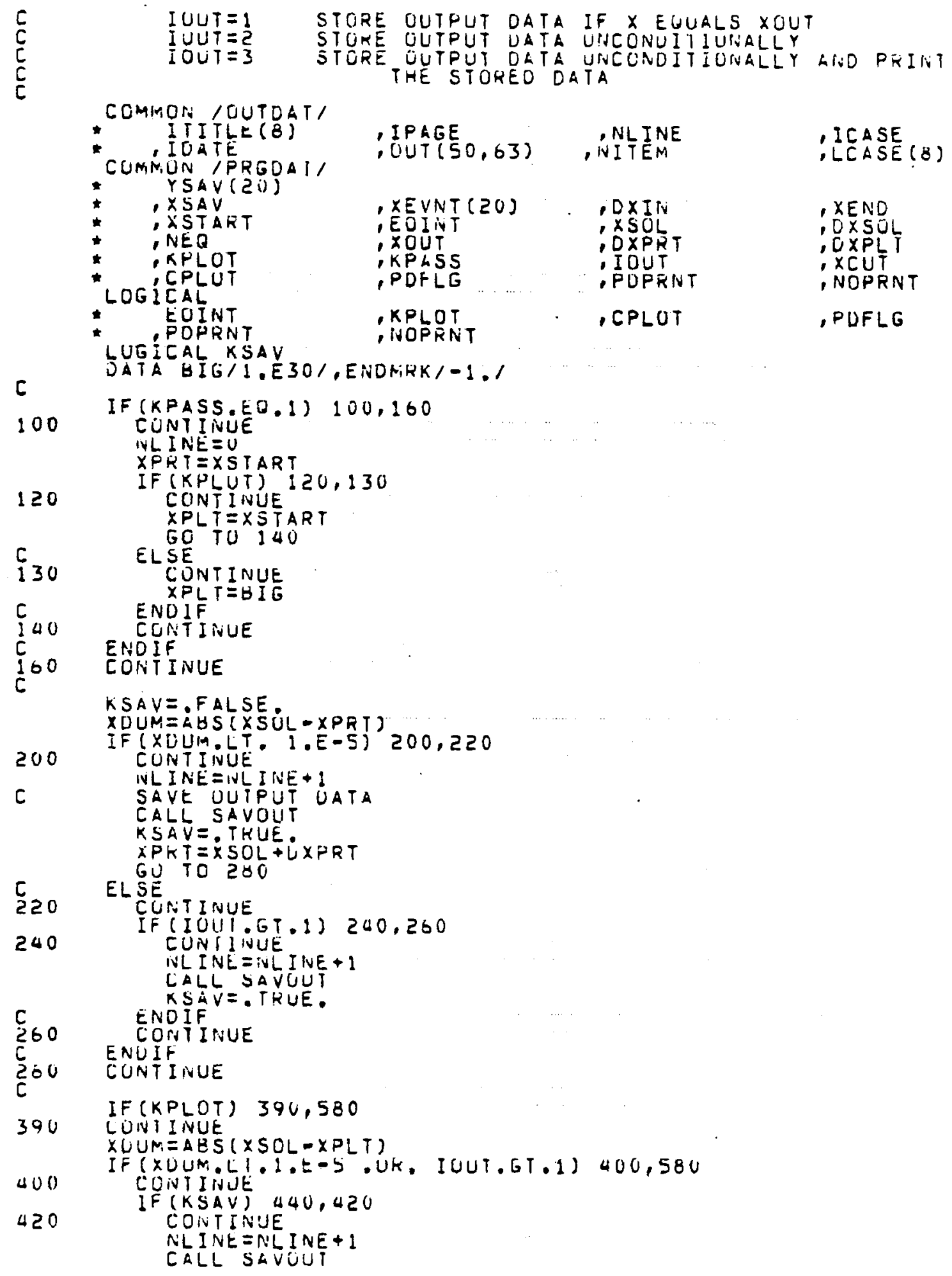




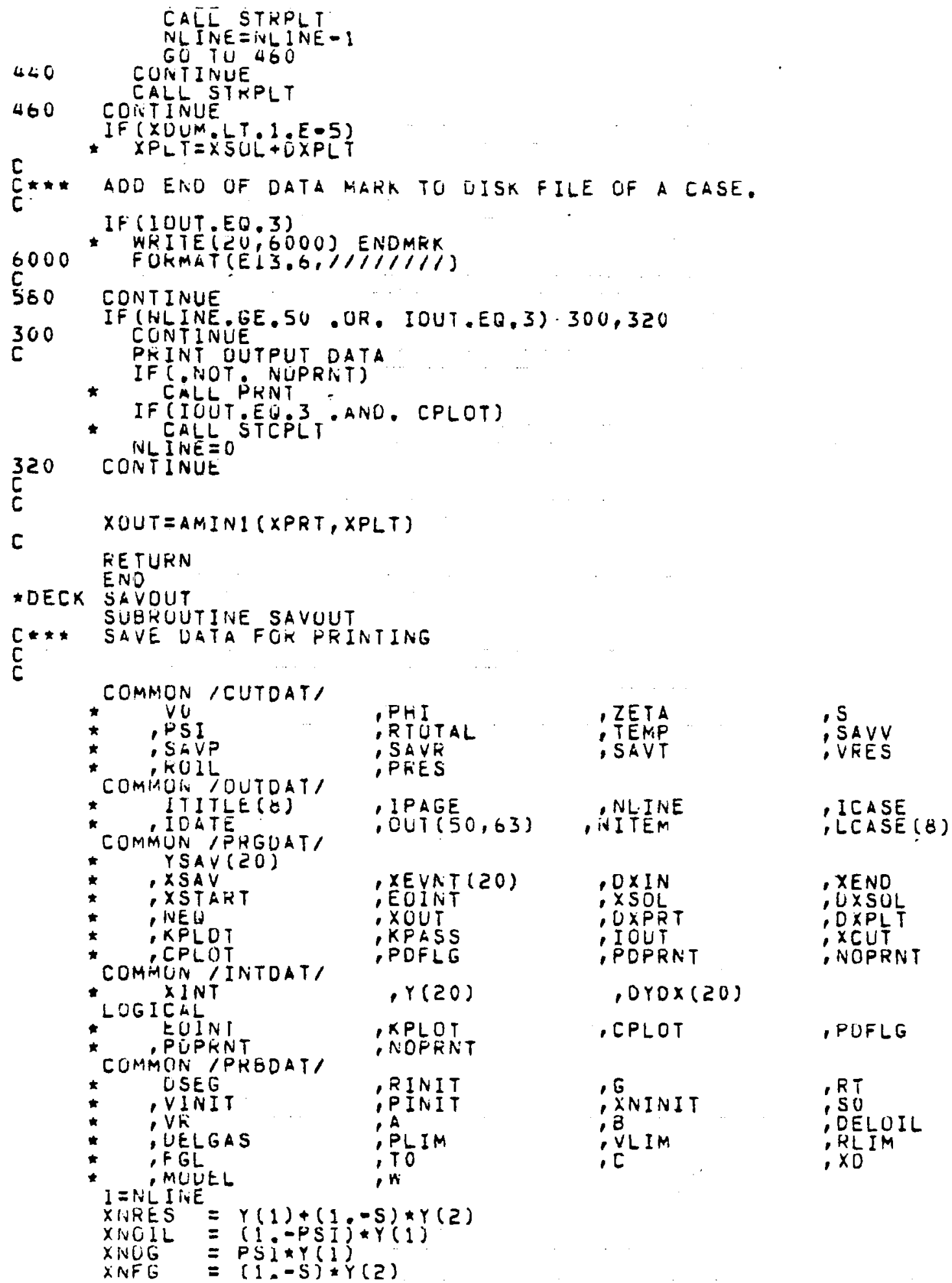




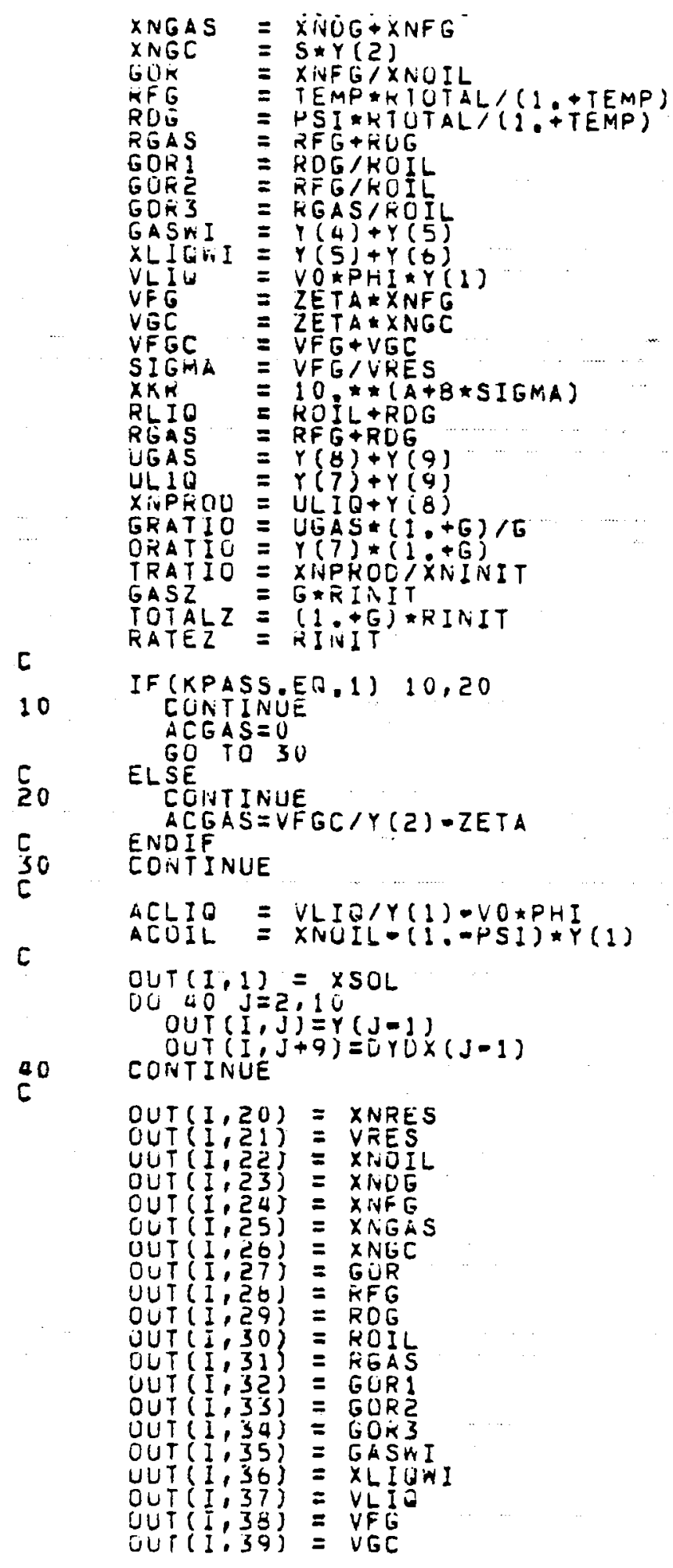




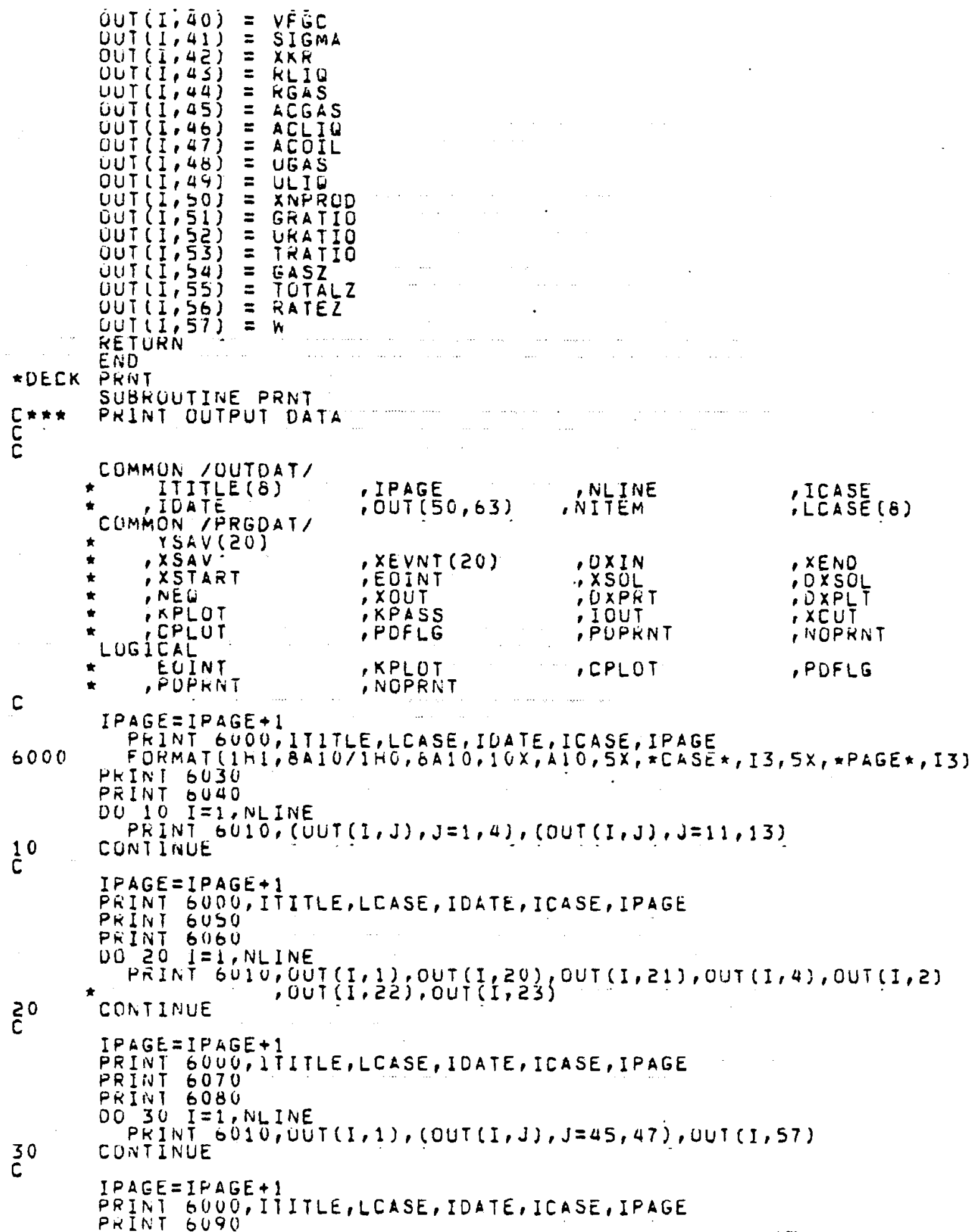




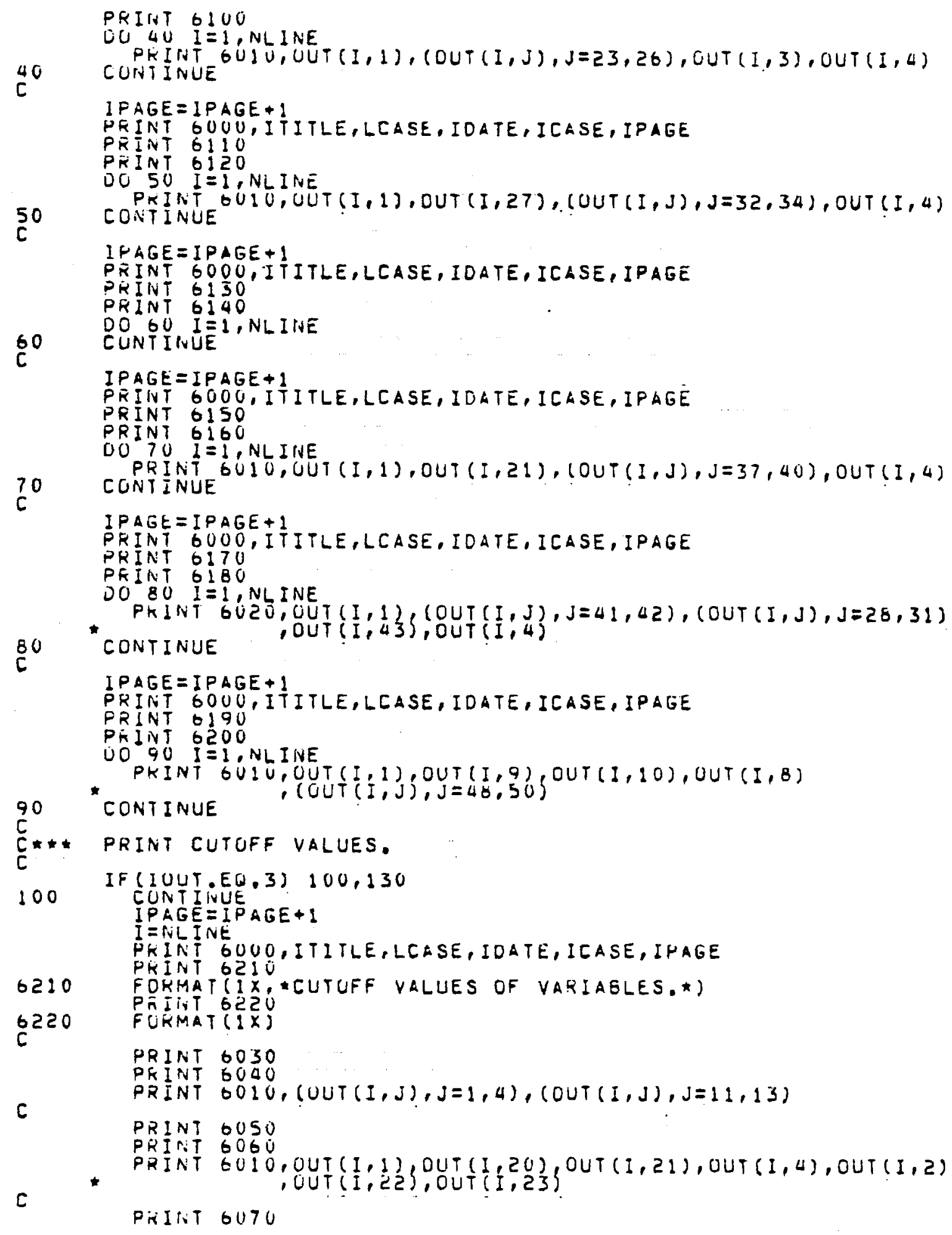




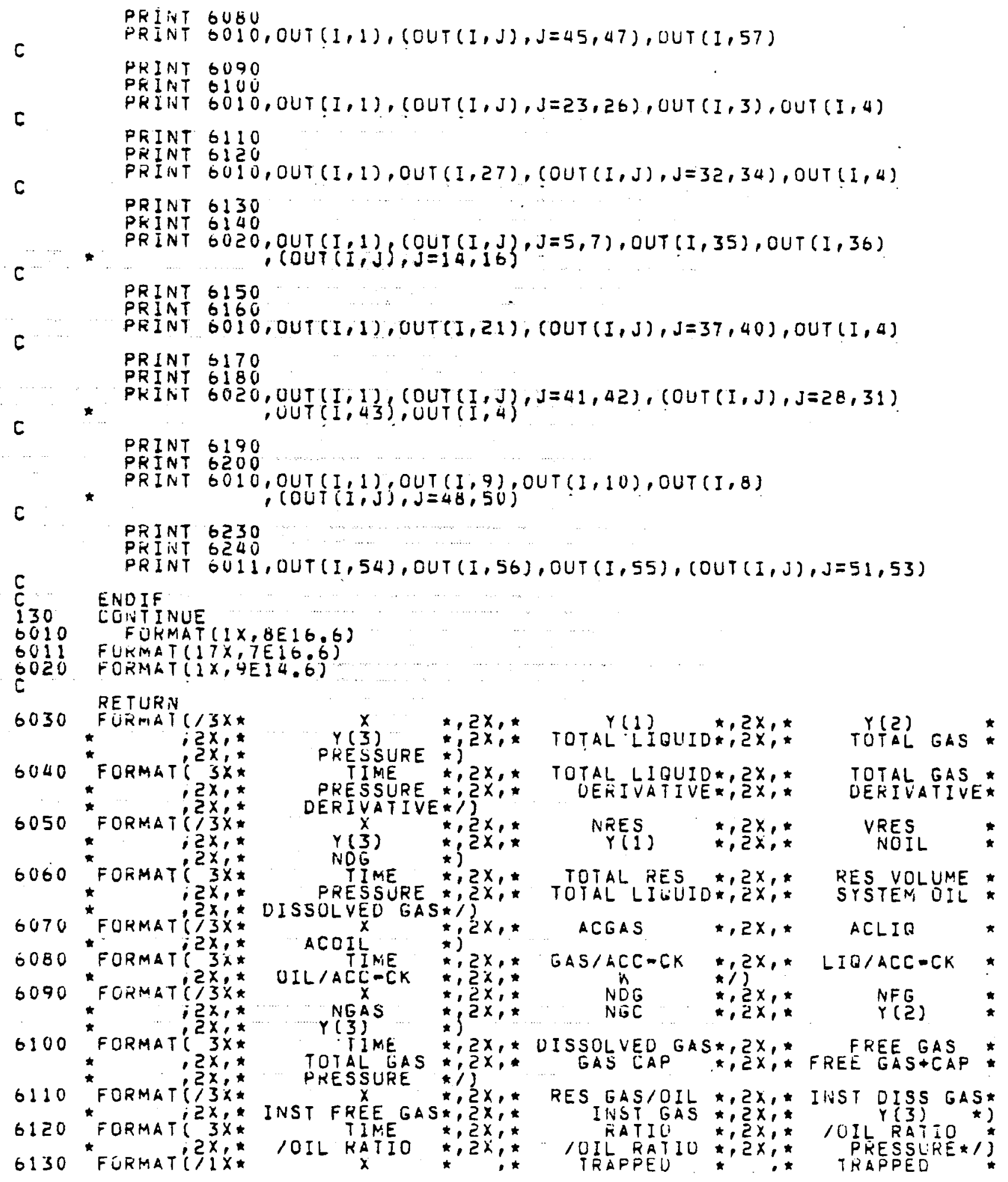




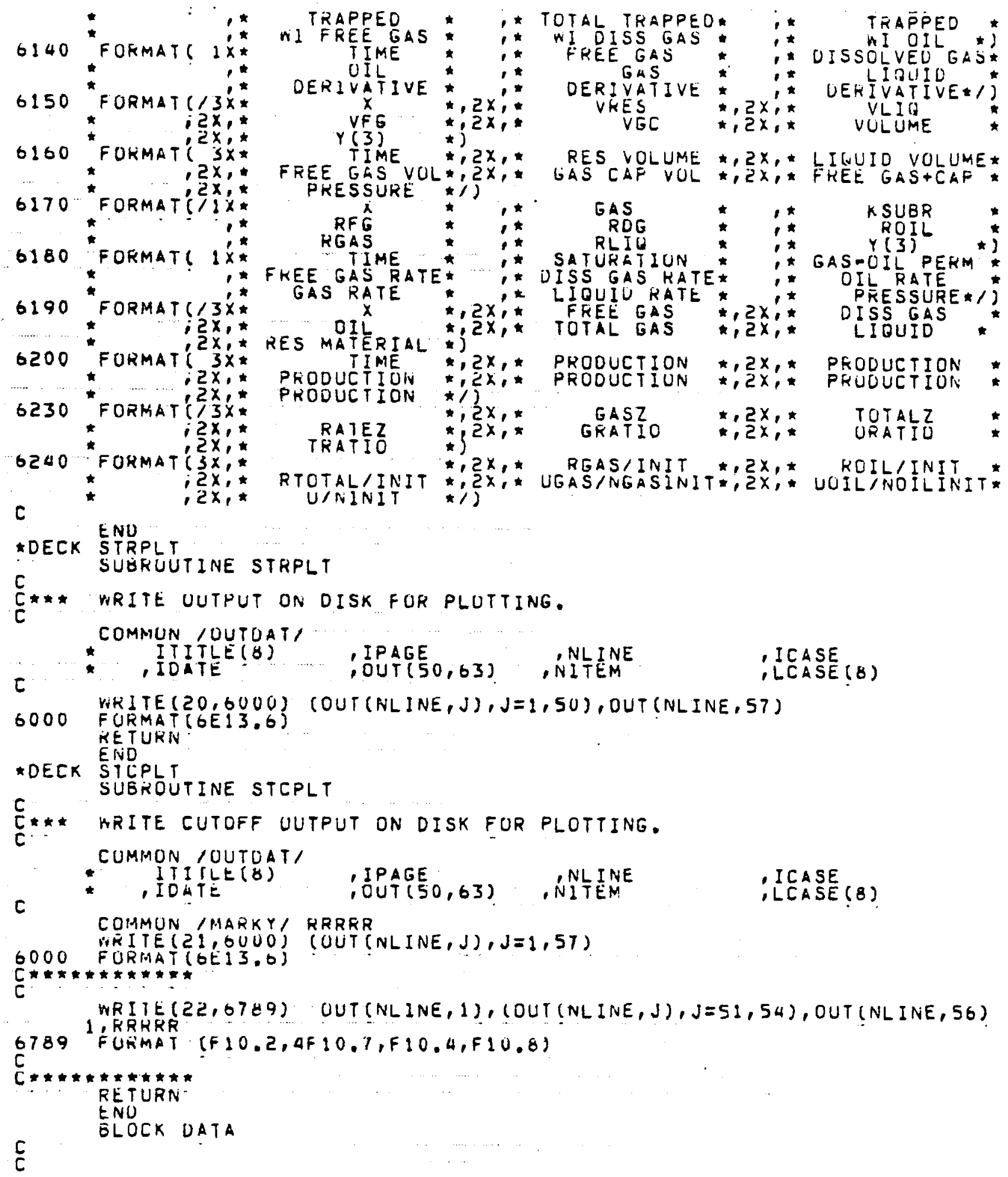




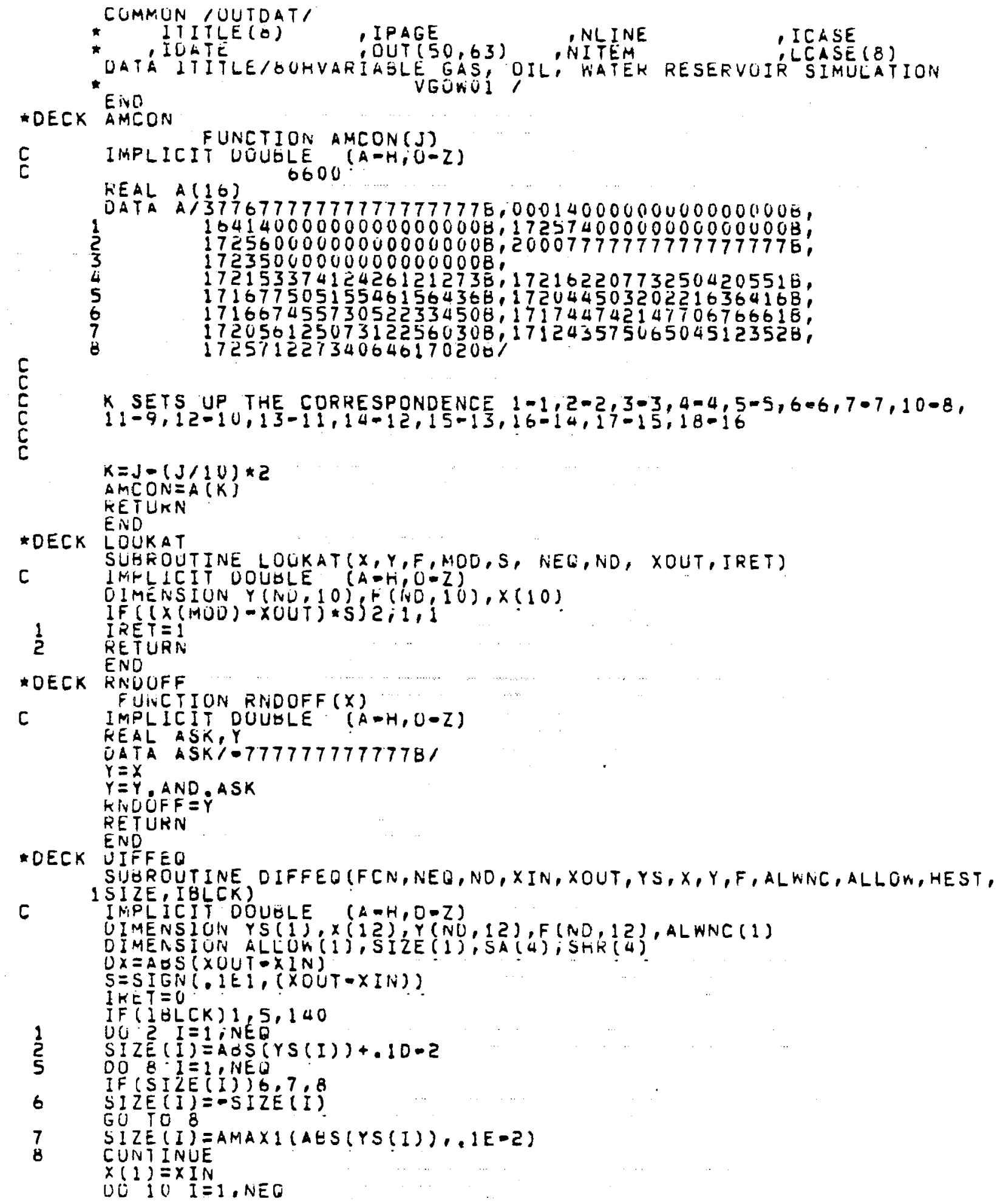




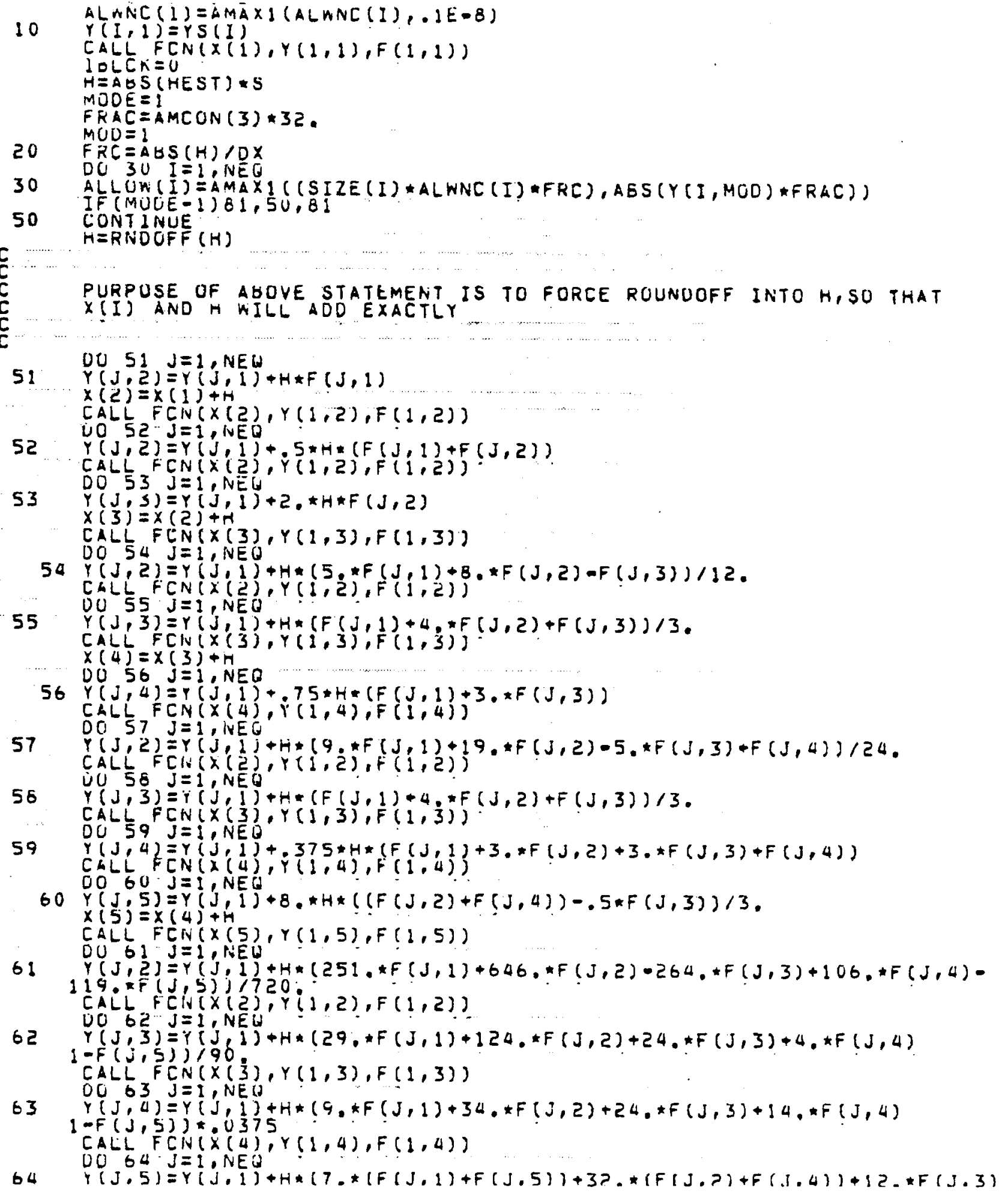


1) 位它乌

CALL FCIN $(X(5), Y(1,5), F(1,5))$

$x(b)=x(5 j+H$

65

UU OS $J=1$. NE 6

$185 . * F\{J, 5\}\}>1440$

CALL F Civ $(X(6), Y(1,6), F(1,6))$

66

DO

$1-17,2)=Y(J, 1)+4 *(475 * * F(J, 1)+1427 \cdot * F(J, Z)-798 \cdot * F(J, 3)+482, * F(J, 4)$

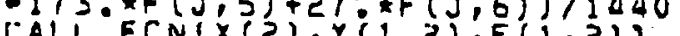

DO FCN $(x(2), Y(1,2), F(1,2))$

$67 \quad Y(J \circ)=1, N E O$

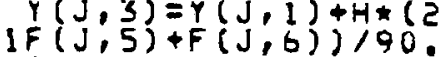

$C A L L F C N(X(3) ; Y(1 ; 3), F(1,3))$

$0068 \mathrm{~J}=1$, $\mathrm{NE}$.

$68 Y(J, 4)=Y(J, 1)+H *(51, * F(J, 1)+219 . * F(J, 2)+114 . *(F(J, 3)+F(J, 4))-21 . *$

IF $(J, 5)+3 ; F(J, 6)) 1160$ CALL FCN $(X(4), Y(1,4), F(1,4))$

69 DU $69 \mathrm{~g}=1$, NEO

1) 1 Jis.

CALL FCN $(X(5), Y(1,5), F(1,5))$

70

DU $70 \mathrm{~J}=1, \mathrm{NE}$ I $(F(J, 6)=Y(J, 1)+H *(19, *(F(J, 1)+F(J, 6))+75 . *(F(J, 2)+F(J, 5))+50 . *$

CALL FCN $(X(6), Y(1,6), F(1,6))$

$x(7)=x(0)+H$

$0071 \mathrm{j}=\mathrm{I}$, NEO

$71 Y(J, 7)=Y(J, 1)+.3 * H \star(11, \star(F(J, Z)+F(J, 6))-14 . \star(F(J, 3)+F(J, 5))+26 . \star$ If $(J, 4)$

CALL FCN $X(7), Y(1,7), F(1,7))$

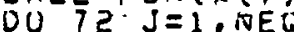

$72 \quad Y(J, 2)=Y(J, j)+H *(19087 * F(J, j)+65112, * F(J, 2)-46461, * F(J, 3)+37504, *$

IF $(J, 4)-202 i j, * F(j, 5)+6 j i 2, F(J, 6)-86 j, * F(j, 7)) / 60460$. CALL FCN $(X(2), Y(1,2), F(j, 2))$

UO $73 \mathrm{~J}=1, \mathrm{NEW}$

73

$Y(J, 3)=Y(J, 1)+H *(1 \geq 39, * F(J, 1)+5640, * F(J, 2)+33, * F(J, 3)+1328, * F(J, 4)$

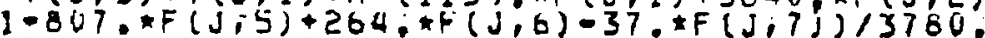

CALL PIN $(X(3), Y(1,3), F(1,3)\}$

UU $7 \Delta, J=1$, IVEU

$Y(J, 4)=Y(J, 1)+H *(685, * F(J, 1)+3240 . * F(J, Z)+1161 * F(J, 3)+2176, *$

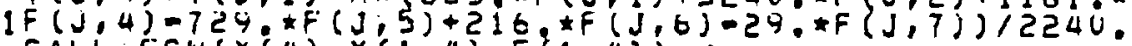
CALL FCN $(X(4), Y(1,4), F(-1,4)\}$

DU $75-J=1$, NEQ

75

$Y(J, S)=Y(J, 1)+H *(286 * F(J, 1)+1392, * F(J, 2)+384 . * F(J, 3)+1504 . *$

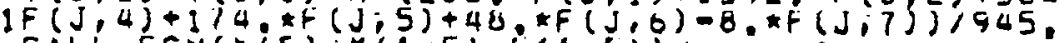
CALL FCN $(x(5) ; Y(1,5), F(1,5)$

76

UO $76 \mathrm{~J}=1$, NEU

$Y(J, 6)=Y(J, 1)+5, * H *(743, * F(J, 1)+3480 * * F(J, 2)+1275, * F(J, 3)+3200 . *$

IF $(J, 4)+2325, * F(J ; 5)+1128, * F(J, 6)-55, * F(J, 7)) / 12096$. CALL FCN $(x(6), Y(1,6), F(1,6))$

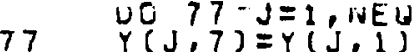

$Y(J, 7)=Y(J, 1)+H *(41 . *(F(J, 1)+F(J, 7))+216 . *(F(J, 2)+F(J, 6))+27 \ldots$

$\left.1(F(j, 3)+F(j, 5))+27 \sum * F(j, 4)\right) / 140$

CALL FCN $(X(7), Y(1,7), F(1,7)\}$

ISI $=1$

I $S \dot{2}=$ ?

I $S 3=3$

I $S 4=4$

I $S 5=5$

is $6=6$

IS $7=7$

601089

EI ISWIT $=0$

8 C ISAIT $=1 S H I T+1$

ISO $=I S W I T=I$ 


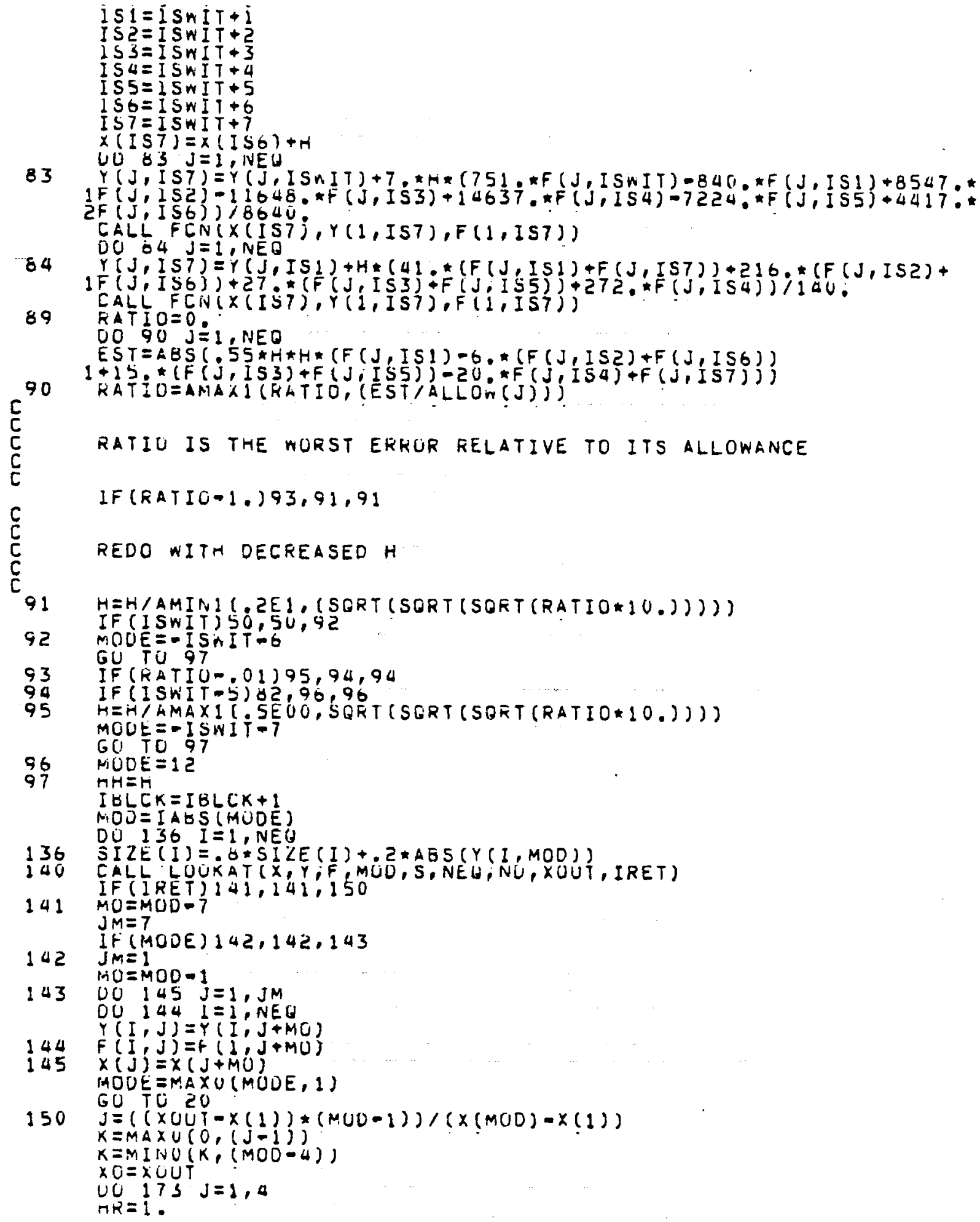




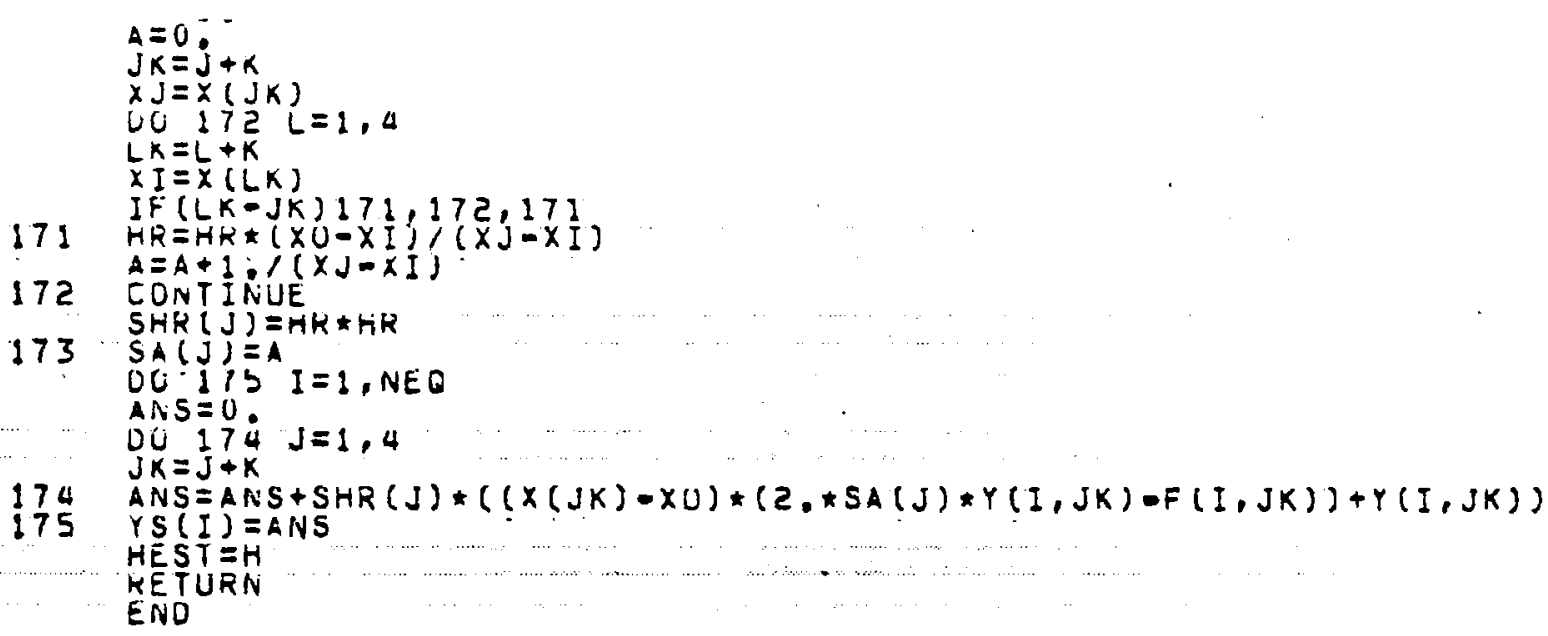




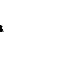




\section{DISTRIBUTION}

No. of

Copies

OFFSITE

A. A. Churm

DOE Patent Division

9800 S. Cass Avenue

Argonne, IL 60439

B. Walker

U.S. Department of the Interior Geological Survey

EGS-Mail Stop 620

Reston, VA 22092

27 DOE Technical Information Center

H. Tomlinson

U.S. Department of the Interior Geological Survey

EGS-Mail Stop 620

Reston, VA 22092

J. Gregory

U.S. Department of the Interior Geological Survey

EGS-Mail Stop 620

Reston, VA 22092

D. Kash

U.S. Department of the Interior Geological Survey

EGS-Mail Stop 620

Reston, VA 22092

25 Dr. J. Lohrenz

U.S. Department of the Interior Geological Survey

Conservation Division

Mail Stop 608

Box 25046, Denver Federal Center

Denver, CO 80225
No. of

Copies

25 E. Monash

U.S. Department of the Interior Geological Survey

Conservation Division

Mail Stop 608

Box 25046, Denver Federal Center

Denver, CO 80225

H. Oden

U.S. Department of the Interior Geological Survey

EGS-Mai1 Stop 620

Reston, VA 22092

Dr. D. Voss

12240 SE 60th

Bellevue, WA 98006

ONSITE

DOE Richland Operations Office

H. E. Ransom

17 Pacific Northwest Laboratory

E. M. Arnold (5)

W. M. Bowen

S. M. Brown

D. B. Cearlock

P. J. Gutnecht

D. W. Mayer

Publishing Coordination (BE)(2)

Technical Information (5) 
,

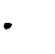

.

9 